\title{
Extension of the Single-Event Microkinetic Model to Alkyl Substituted Monoaromatics Hydrogenation on a Pt Catalyst
}

\author{
Tapan Bera, Joris W. Thybaut,* and Guy B. Marin \\ Laboratory for Chemical Technology, Ghent University, Krijgslaan 281-S5, B-9000 Ghent, Belgium
}

\begin{abstract}
The Single-Event MicroKinetic (SEMK) methodology, which had been successfully applied to benzene hydrogenation on a Pt catalyst, has now been extended toward substituted monoaromatics, that is, toluene and $o$-xylene. The single-event concept combined with thermodynamic constraints allowed to significantly reduce the number of adjustable parameters. In addition to the number of unsaturated nearest neighbor carbon atoms, $\mathrm{H}$-atom addition rate and equilibrium coefficients were assumed to depend on the carbon atom type, that is, secondary or tertiary. This leads to three additional reaction families compared to benzene hydrogenation. Gas phase toluene and $o$-xylene hydrogenation experiments were performed on 0.5 wt \% Pt/ZSM-22 in a temperature range from 423 to 498 $\mathrm{K}$, a total pressure range from 1 to $3 \mathrm{MPa}, \mathrm{H}_{2}$ inlet partial pressures between 100 and $600 \mathrm{kPa}$ and aromatic inlet partial pressures between 10 and $60 \mathrm{kPa}$. A simultaneous regression of the SEMK model to an experimental data set consisting of 39

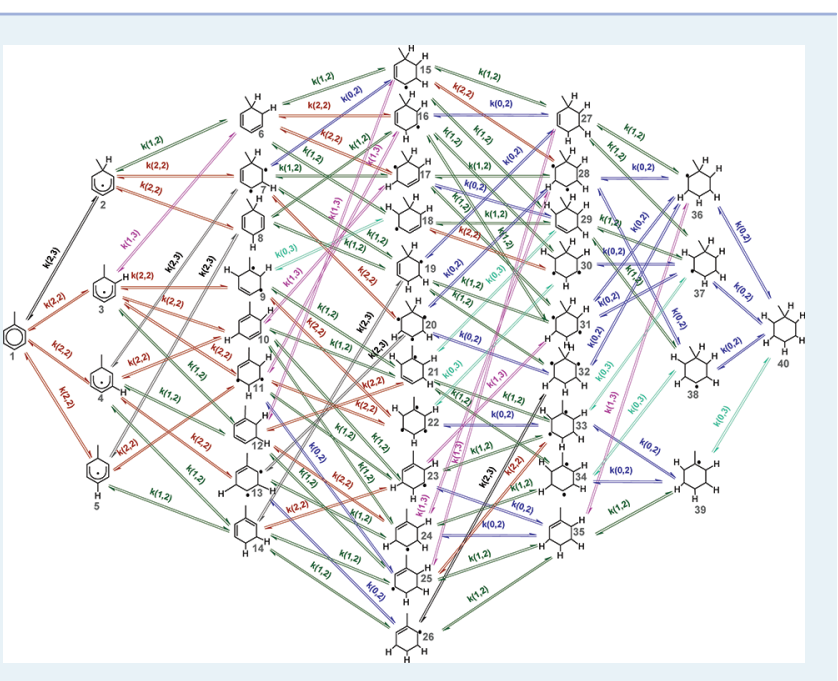
toluene and 370 -xylene hydrogenation experiments resulted in activation energies of $\mathrm{H}$ additions to tertiary carbon atoms that are $10.5 \mathrm{~kJ} \mathrm{~mol}^{-1}$ higher than to secondary carbon atoms. This can be related to the steric hindrance experienced during $\mathrm{H}$ addition to a carbon atom bearing a substituent. The presence of a substituent on the aromatic ring was found not to affect the chemisorption enthalpies. The reaction path analysis has been carried out via differential contribution analysis and identified that the hydrogenation first occurs at secondary carbon atoms prior to the hydrogenation of the tertiary carbon atoms in the hydrogenation sequence. This is in line with the distribution of hydrocarbon species on the catalyst surface.
\end{abstract}

KEYWORDS: hydrogenation, monoaromatics, toluene, o-xylene, platinum, noble metal, single-event microkinetic modeling

\section{INTRODUCTION}

Both quality and environmental concerns continue to impose stringent restrictions on the aromatics content of transportation fuels. Hydrocracking of heavier petroleum fractions is one of the most important processes in the refining industry for the production of high quality fuels. Typical hydrocracking feeds contain a significant aromatics fraction. The high aromatics content in distillate fuels lowers their quality and contributes significantly to the formation of environmentally harmful emissions. ${ }^{1}$ The reduction of the aromatics concentration in diesel increases the cetane number and generally improves combustion characteristics. The catalytic hydrogenation of aromatic compounds is an important reaction to overcome these constraints. The increased interest from refiners in diesel desulfurization and dearomatization has resulted in numerous investigations on hydrogenation of model molecules and complex mixtures over different types of catalysts. Abundant literature concerning monoaromatics hydrogenation over various catalysts is available. The hydrogenation of benzene, biphenyl, tetralin, and its alkyl derivatives have been studied over sulfided catalysts (Mo, NiMo, CoMo, NiW, FeMo $)^{2-5}$ as well as on supported noble metal catalysts. ${ }^{6-8}$ Supported noble metal catalysts are well-known for their higher hydrogenation activity but also for their susceptibility to sulfur poisoning and, hence, are typically only used in the second stage of present-day commercial hydrotreating processes aiming at deep aromatics hydrogenation. $^{9}$

Kinetic models play a critical role in process and catalyst design, development, and optimization. Numerous kinetic models have been proposed in attempts to capture laboratory experimental data on aromatics hydrogenation. These models are either power law models in their most simple form, which typically limits their application to a restricted range of process conditions, or more fundamental Langmuir-HinshelwoodHougen-Watson (LHHW) type of models considering a ratedetermining step (RDS) which may depend upon the feedstock considered or also on the operating conditions. Some authors proposed the addition of the first $\mathrm{H}_{2}$ molecule or the simultaneous addition of the first two $\mathrm{H}$ atoms as rate determining. ${ }^{10-13}$ Lin and Vannice ${ }^{14}$ selected a model where

Received: January 24, 2012

Revised: April 4, 2012

Published: May 9, 2012 
the first $\mathrm{H}$-atom addition was rate determining for benzene and toluene hydrogenation on supported Pt catalyst. Other authors proposed a model with equal rate coefficients for all hydrogenation steps. ${ }^{13,15}$ Thybaut et al. ${ }^{16}$ constructed a model with equal surface reaction rate coefficients up to the fourth $\mathrm{H}$ addition step for toluene hydrogenation data on Pt/ZSM-22. A LHHW type of kinetic model for the same data set was also developed based on a detailed first-principles density functional theory calculations and corresponding reaction path analysis. ${ }^{17,18}$

The Single-Event MicroKinetic (SEMK) methodology goes beyond the above-mentioned types of kinetic models by explicitly accounting for the rates of all elementary steps that are considered in the reaction mechanism and not assuming a rate-determining step. The adequate classification of elementary steps into reaction families ensures the feedstock independence of the corresponding kinetic parameters. ${ }^{19}$ It is believed that SEMK models offer the ability to cover a broader range of operating conditions as the entire reaction network is being considered, along with improved accuracy. The SEMK methodology based upon elementary steps has been developed and applied mainly for acid catalyzed reaction steps such as isomerization, cracking, and alkylation of hydrocarbons in the methanol-to-olefins (MTO) process, ${ }^{20}$ catalytic cracking, ${ }^{21-23}$ or Hydrocracking. ${ }^{24-28}$ The SEMK methodology has since been extended to metal catalyzed reactions with Fischer-Tropsch synthesis as example reaction. ${ }^{29}$ More recently, the same methodology has been developed and validated for benzene hydrogenation on a $\mathrm{Pt}$ catalyst based on atomic $\mathrm{H}$ addition to the (partially hydrogenated) aromatic species on the catalyst surface. $^{30}$

In this work, the SEMK methodology as developed for benzene hydrogenation is further extended toward substituted monoaromatics. The hydrogenation of toluene and $o$-xylene over a Pt catalyst is used to assess the model parameters related to tertiary carbon atoms. Relying on the single-event concept and the corresponding feed independence of the model parameters, the values obtained for $\mathrm{H}$ addition to secondary carbon atoms in the benzene hydrogenation study ${ }^{30}$ are used without further adjustments in the regression of the toluene and $o$-xylene hydrogenation data set. A set of physically significant activation energies and reaction enthalpies was determined by regression while pre-exponential factors were calculated a priori using statistical mechanics. Of course, the thermodynamic consistency of the parameter values was guaranteed. The challenge is to elucidate the detailed surface hydrogenation reaction mechanism and to identify a potential dominant reaction path or the occurrence of potentially rate-determining steps.

\section{PROCEDURES}

2.1. Catalyst. A 0.5 wt \% Pt on ZSM-22 catalyst was used to investigate aromatics hydrogenation. The zeolite was calcined, exchanged with ammonium cations, and impregnated with an aqueous solution of $\mathrm{Pt}\left(\mathrm{NH}_{3}\right)_{4} \mathrm{Cl}_{2}$ to obtain $0.5 \mathrm{wt} \% \mathrm{Pt}$ loading. ${ }^{16,31}$ The deposited $\mathrm{Pt}$ metal clusters with a diameter of $3 \mathrm{~nm}$ were located on the external surface of zeolite crystallites as the narrow micropores of the zeolite only have a cross section of $0.45 \mathrm{~nm} \times 0.55 \mathrm{~nm}$. Hence, the hydrogenation occurred in the intercrystalline pores of the zeolite, devoid of any shape selectivity. Consecutive acid catalyzed isomerization and cracking reactions were suppressed because of the shapeselective character of the intracrystalline pores of the zeolite and the corresponding pore mouths. The total concentration of active sites was determined at $1 \times 10^{-2} \mathrm{~mol} \mathrm{~kg}_{\mathrm{cat}}{ }^{-1}$ which corresponds to the number of accessible Pt atoms. ${ }^{16,30}$ The use of catalyst pellets with diameters between 0.8 and $1.0 \mathrm{~mm}$ was sufficient to avoid diffusion limitations. These catalyst pellets were prepared by compressing the dry zeolite powder into flakes and subsequent crushing and sieving. The catalyst was calcined in oxygen and afterward reduced in hydrogen at $673 \mathrm{~K}$. More details about the catalyst have been reported in previous publications. ${ }^{16,30}$

Aromatics hydrogenation is reported to be a structureinsensitive reaction and, hence, the catalyst activity only depends upon the total number of surface metal atoms and does not depend upon metal dispersion, crystal plane, or defect structure. ${ }^{32,33}$ As a result, no (significant) material gap should exist in the case of aromatics hydrogenation on $\mathrm{Pt}$, and mechanistic insights remain valid beyond the laboratory scale testing as discussed in the present work.

2.2. Setup and Operating Conditions. Toluene (Acros Organics, 99\%) and o-xylene (Acros Organics, 99\%) were selected as substituted model aromatic compounds and hydrogenated in separate experiments in a Berty type reactor which is of the continuous stirred tank reactor (CSTR) type. The reactor set up has been described in previous work. ${ }^{34}$ Nitrogen (Air Liquide, 99.8\%) was used along with hydrogen (Air Liquide, 99.99\%, $\mathrm{H}_{2} \mathrm{O}$ and $\mathrm{O}_{2}$ content $<10 \mathrm{ppm}$ ), and the selected model hydrocarbon compound to establish the desired hydrogen and hydrocarbon partial pressures. Methane (Air Liquide, 99.9\%) was used as internal standard to calculate the hydrocarbon outlet flow rates for the verification of the carbon and mass balance over the reactor. On line analysis of the reactor effluent sample was performed using an HP series II 5890 gas chromatograph equipped with a $50 \mathrm{~m}$ (i.d. $=0.25 \mathrm{~mm}$.) RSL-150 column with a $0.25 \mu \mathrm{m}$ poly dimethylsiloxane film after $1 \mathrm{~h}$ stabilization time of the equipment. A small $\mathrm{H}_{2}$ flow was sent through the reactor to avoid significant catalyst deactivation between two experimental runs as a slight decrease in catalytic activity was observed in experimental runs of 2 to $4 \mathrm{~h}$. Only experiments with values for total mass and carbon balance between $95 \%$ and $105 \%$ are retained. In the further treatment of the data, the outlet flow rates were normalized to a $100 \%$ carbon balance. ${ }^{16}$ A total of 39 and 37 experiments were carried out for toluene and $o$-xylene hydrogenation respectively with varying temperature, total pressure, $\mathrm{H}_{2}$ inlet partial pressure, molar $\mathrm{H}_{2}$ to aromatics inlet ratio and space time as specified in Table 1 .

Table 1. Range of Experimental Conditions in Aromatics Hydrogenation Experiments

\begin{tabular}{lll}
\multicolumn{1}{c}{ experimental hydrogenation conditions } & toluene $\mathrm{e}^{16}$ & $o$-xylene \\
temperature $(\mathrm{K})$ & $423-498$ & $423-473$ \\
total pressure $(\mathrm{MPa})$ & $1.0-3.0$ & $1.0-3.0$ \\
inlet $\mathrm{H}_{2}$ partial pressure $(\mathrm{kPa})$ & $10-60$ & $10-60$ \\
inlet molar $\mathrm{H}_{2}$ to aromatics ratio $\left(\gamma_{\mathrm{H} 2 / \mathrm{Aro}}\right)$ & $5-10$ & $5-10$ \\
space time $\left(\mathrm{kg}_{\mathrm{cat}} \mathrm{s} \mathrm{mol}-1\right)$ & $27-82$ & $29-90$ \\
conversion range $(\mathrm{mol} \%)_{\text {number of experiments }}^{5-74}$ & $0.8-59$ \\
\end{tabular}

The absence of mass transport limitations in intercrystalline pores was verified by calculating Weisz moduli $\left(\sim 10^{-2}\right)$ for all the experimental runs. ${ }^{35,36}$ As hydrogenation occurred on the external crystallite surface, intracrystalline diffusion is not relevant. ${ }^{16}$ The operating conditions, together with reactant and reactor type were selected to measure intrinsic kinetics, free from transport limitations and reactor flow pattern nonidealities. 
The catalyst performance reproducibility was confirmed by repeating some experiments on two different catalyst batches immediately after activation as well as on the same catalyst batch after performing a series of experiments.

Results are reported in terms of the aromatics reactant conversion which was calculated as follows:

$$
X=\frac{F_{\mathrm{A}}^{0}-F_{\mathrm{A}}}{F_{\mathrm{A}}^{0}}
$$

Where $F_{\mathrm{A}}^{0}$ and $F_{\mathrm{A}}$ represent the aromatics inlet and outlet molar flow rates.

2.3. Parameter Estimation. The estimation of the kinetic parameters was performed by minimizing the sum of squares of the residuals between the experimentally observed and model calculated responses. In the present work the molar outlet flow rate of the product cycloalkane was used as a single response. It was modeled by adjusting the model parameter vector $\boldsymbol{b}$, which is expected to approach the real parameter vector $\boldsymbol{\beta}$ when the optimum is reached.

$$
S S Q=\sum_{j=1}^{n o b}\left(F_{\mathrm{CA}, j}-\hat{F}_{\mathrm{CA}, j}\right)^{2} \stackrel{b}{\rightarrow} \text { Min }
$$

Here $F_{C A, j}$ is the experimentally observed molar outlet flow rate for the cycloalkane produced by hydrogenation of the corresponding aromatic compound in the $j$ th experiment and $\hat{F}_{\mathrm{CA}, j}$ is the corresponding, model calculated value. An implementation of the Levenberg-Marquardt algorithm, that is, the "ordinary least-squares" (OLS) option of the ODRPACKpackage version 2.01 was used to perform the minimization. ${ }^{37,38}$ Some additional source code was added to ODRPACK to retrieve additional statistical information.

For a given kinetic model, the cycloalkane molar outlet flow rate is calculated by solving the non linear equation

$$
\hat{F}_{\mathrm{CA}, j}-\hat{R}_{\mathrm{CA}, j}\left(T, p_{t}, \hat{F}_{\mathrm{CA}, j}, F_{\mathrm{A}}^{0}\right) W_{j}=0
$$

that is, via the mass balance for this cycloalkane over the reactor, if the latter is not fed. The cycloalkane net production rate is calculated from the kinetic model, which gives rise to a set of algebraic equations, discussed in section 4.3. These algebraic equations are solved simultaneously with the mass balance equation using a hybrid Powell method. ${ }^{39}$

The iterative procedure for parameter estimation began by performing simulations to obtain good initial guesses of the parameters. Once simulation results were within 1 order of magnitude of the experimental ones, an optimization procedure was initiated in which successive iterations according to the Levenberg-Marquardt algorithm were performed for ultimate parameter estimation. Prior to this regression, as many parameters as possible were calculated from first principles or were related to each other via thermodynamic constraints, see also Section 4.4.

The significance of the regression is tested by the calculation of the ratio of the regression sum of squares and the residual sum of squares divided by their respective degrees of freedom, that is, the so-called $\mathrm{F}$ test for the global significance of the regression. A high $\mathrm{F}$ value corresponds to a high significance of the global regression. The estimated parameters are also tested for statistical significance on the basis of their individual $t$ values, which are related to the sensitivity of the model calculations on the values of the individual parameters. A parameter is estimated significantly different from zero when its individual $t$ value is higher than the corresponding tabulated $\mathrm{t}$ value, given by $t_{\text {nob nresp-npar }}(0.95)$. A high $t$ value corresponds to a high sensitivity to the corresponding parameter and, hence, a high significance or a narrow $95 \%$ approximate individual confidence interval of the corresponding parameter. The model discrimination was based on the physical meaning of the parameters and by comparison of the global regression results through the obtained $F$ value.

2.4. Contribution Analysis. A contribution analysis is a useful tool to obtain insight in a complex reaction network. ${ }^{40} \mathrm{~A}$ differential contribution analysis has been carried out to assess the relative importance of the various elementary steps in the reaction network. The differential disappearance contribution factor $(\phi)$ of reaction step $l$ toward the disappearance of component $j$ is defined as the ratio of the rate of disappearance of component $j$ resulting from reaction $l$ to the total rate of disappearance of component $j$ via all reaction steps $k$ in which component $j$ is consumed:

$$
\phi_{l, j}^{\mathrm{d}}=\frac{r_{l, j}^{\mathrm{d}}}{\sum_{k} r_{k, j}^{\mathrm{d}}}
$$

The contribution analysis is typically carried out corresponding to a given conversion of the feed component at a certain position inside the reactor, that is, at a certain composition of reaction mixture. The analysis is used to quantify the relative importance of various elementary steps occurring in the reaction network. This methodology is based on reaction rates and, hence, accounts for the effects of rate coefficients and of surface concentration of reactant species. ${ }^{41}$ Note that in case of a CSTR, no distinction has to be made between a differential and integral contribution analysis.

\section{EXPERIMENTAL RESULTS: EFFECT OF THE OPERATING CONDITIONS ON HYDROGENATION}

The main reaction products of the hydrogenation of toluene and $o$-xylene were methylcyclohexane $(\mathrm{MCH})$ and 1,2-dimethylcyclohexane $(\mathrm{DMCH})$ respectively. cis- and trans-1,2-Dimethylcyclohexane isomers are formed during hydrogenation of $o$-xylene. An adequate description of the stereochemistry goes beyond the scope of the current work; however, and, hence, cis- and trans1,2-dimethylcyclohexane isomers are lumped into a single DMCH outlet flow rate. Neither partially hydrogenated products such as alkylcyclohexadienes and alkylcyclohexenes nor ringopening products were observed. Only minor amounts $(<5 \%)$ of alkyl cyclopentanes and 1,3- and 1,4-dimethylcyclohexanes were formed by the consecutive isomerization of the product alkylcyclohexane at Brönsted acid sites located at ZSM-22 pore mouths. Isomerization reactions are restricted by the shape selectivity induced by ZSM-22 framework as well as by the larger time scale required for this reaction compared to the hydrogenation reaction. Hence, for all practical purposes, the present study can be limited to the selective hydrogenation of toluene and $o$-xylene to methylcyclohexane and dimethylcyclohexane, respectively, and the amounts of cycloalkane isomers observed were added to the corresponding cycloalkane response.

The effect of the operating conditions on the toluene and $o$ xylene conversion is consistent with what is typically reported in the literature. ${ }^{13,14,16,30,42,43}$ The conversion showed a maximum as a function of the temperature, see Figure 1. From the optimum temperature onward, the increase of the hydrogenation rate coefficient with the temperature is overcompensated by the decrease of the surface concentrations of the (partially hydrogenated) aromatic species. Mass transport limitations 


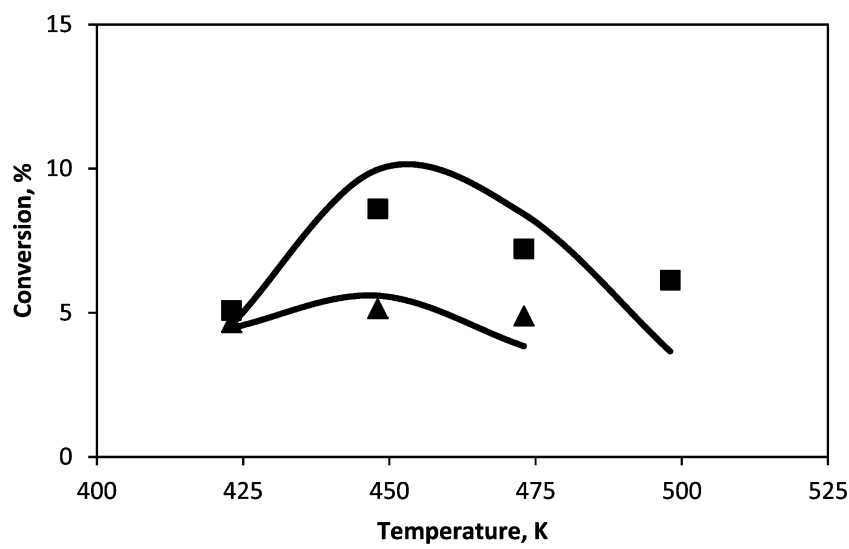

Figure 1. Toluene $(\boldsymbol{\square})$ and $o$-xylene $(\boldsymbol{\Lambda})$ conversion as a function of temperature at a total pressure of $1 \mathrm{MPa}$. Symbols: experimentally observed values. Lines: calculated based on the net rate of hydrogenation eq 7 and reactor model eq 3 with the pre-exponential factors from Table 2 and the activation energies and reaction enthalpies from Table 4. Reaction conditions: Toluene hydrogenation: $p_{\mathrm{T}}^{0}=20.3 \mathrm{kPa}$,

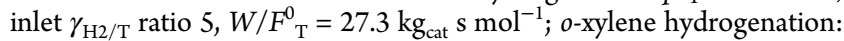
$p_{\mathrm{X}}^{0}=10.1 \mathrm{kPa}$; inlet $\gamma_{\mathrm{H} 2 / \mathrm{X}}$ ratio $10, W / F_{\mathrm{X}}^{0}=29.8 \mathrm{~kg}_{\mathrm{cat}} \mathrm{s} \mathrm{mol}^{-1}$.

cannot be invoked to explain the phenomenon as the intrinsic character of the kinetic data was verified. Other possible causes, such as thermodynamic limitations and catalyst poisoning have also been verified and can be discarded. ${ }^{8,13}$

An increase in the hydrogen inlet partial pressure enhances the aromatics hydrogenation, see Figure $2 .{ }^{16,30}$ Hydrogen partial reaction orders have been determined previously for toluene hydrogenation and range from 0.6 at $423 \mathrm{~K}$ over 1.1 and 1.8 at 448 and $473 \mathrm{~K}$ to 1.3 at $498 \mathrm{~K}^{16}$ The increase in hydrogen inlet partial pressure keeping all other experimental variables fixed results in a corresponding increase of the hydrogen surface concentration and, hence, an enhanced cyclohexane outlet flow rate at all temperatures. Hydrogen partial reaction orders also allow identifying the position of a rate-determining step, if any, in the reaction mechanism. The hydrogen partial reaction order amounts to 0.5 if the most abundant surface intermediate is consumed in the rate-determining step. For every additional hydrogen addition required to form the surface intermediate that is consumed in the rate-determining step out of the most abundant surface intermediate, the hydrogen partial reaction order increases by 0.5 . As a result hydrogen partial reaction orders up to 1.8 indicate that at least 3 to 4 hydrogen additions need to occur prior to a possible rate-determining step, which, hence, if it occurs at all, will be situated near the end of the hydrogenation sequence on the catalyst surface.

An opposite effect, that is, no effect or negative effect is observed for the aromatics inlet partial pressure, see Figure $3{ }^{16,30}$ The corresponding partial reaction orders for toluene have been determined at -0.2 at 423 and $448 \mathrm{~K}$ and increase to -0.1 at 473 and to 0.3 at $498 \mathrm{~K}^{16}$ The negative partial reaction orders at the lower temperatures are indicative of inhibition effects, that is, the higher surface concentration of partially hydrogenated species at higher aromatic inlet partial pressures is significantly hindering the hydrogen chemisorption. The expected increase in hydrogenation conversion because of the higher surface concentrations of the partially hydrogenated intermediates is overcompensated by a corresponding decrease in hydrogen surface concentration. As a result a decrease in hydrogenation conversion is observed with increasing aromatics inlet partial pressure. The higher aromatic partial reaction order at higher temperatures is a logical

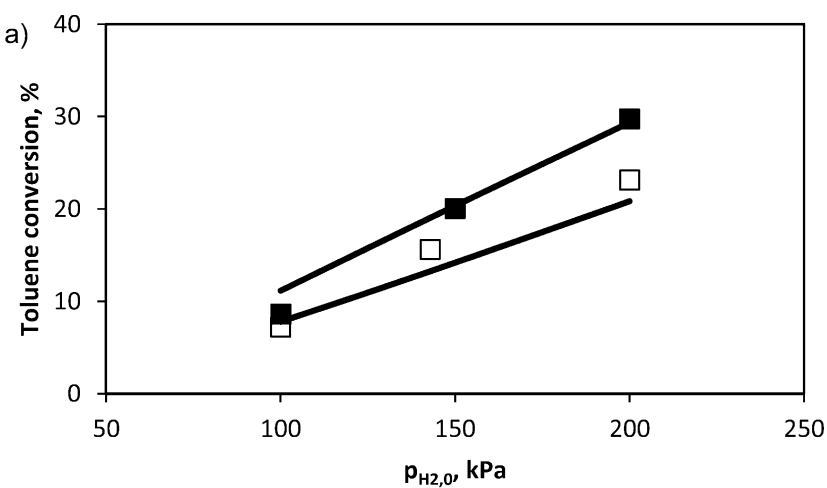

b)

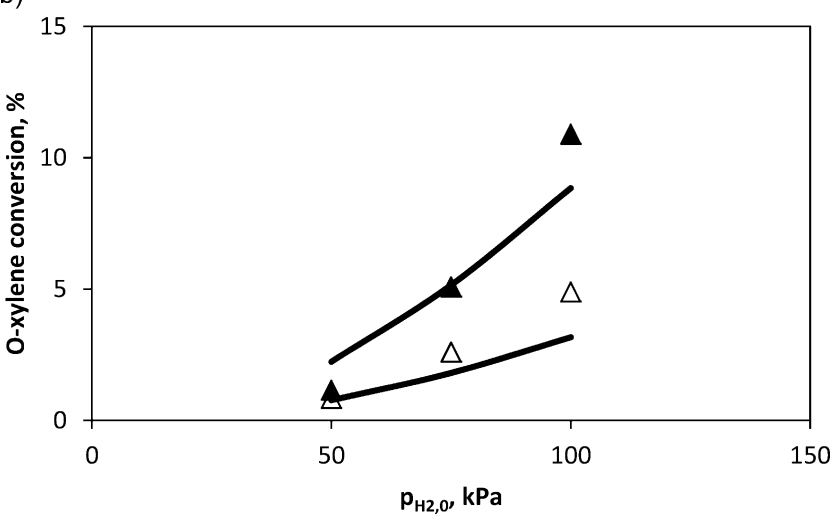

Figure 2. Effect of hydrogen inlet partial pressure on (a) toluene and (b) $o$-xylene conversion at a total pressure $1 \mathrm{MPa}$. Symbols: experimentally observed values. Lines: calculated based on the net rate of hydrogenation eq 7 and reactor model eq 3 with the pre-exponential factors from Table 2 and the activation energies and reaction enthalpies from Table 4. Reaction conditions: (a) $p_{\mathrm{T}}^{0}=20 \mathrm{kPa} ; T=473 \mathrm{~K} ; W / F_{\mathrm{T}}^{0}=40.9$ $\mathrm{kg}_{\text {cat }} \mathrm{s} \mathrm{mol}^{-1}(\boldsymbol{\square}), 27.3 \mathrm{~kg}_{\mathrm{cat}} \mathrm{s} \mathrm{mol}{ }^{-1}(\square)(\mathrm{b}) p_{\mathrm{X}}^{0}=10 \mathrm{kPa} ; T=473 \mathrm{~K} ; W /$ $F_{\mathrm{X}}^{0}=89.3 \mathrm{~kg}_{\mathrm{cat}} \mathrm{s} \mathrm{mol}^{-1}(\mathbf{\Lambda}), 29.8 \mathrm{~kg}_{\mathrm{cat}} \mathrm{s} \mathrm{mol}^{-1}(\Delta)$.

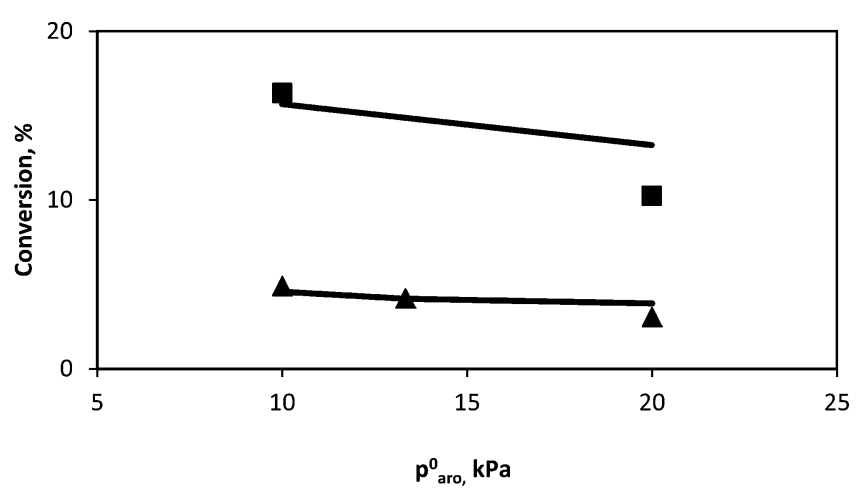

Figure 3. Toluene $(\boldsymbol{\square})$ and $o$-xylene $(\boldsymbol{\Delta})$ conversion as a function of aromatics inlet pressure. Reaction conditions: $p_{\mathrm{t}}=1 \mathrm{MPa}, T=473 \mathrm{~K}$, $p^{0}{ }_{\mathrm{H} 2}=100 \mathrm{kPa}, W / F_{\mathrm{T}}^{0}=81.8 \mathrm{~kg}_{\mathrm{cat}} \mathrm{s} \mathrm{mol}{ }^{-1}, W / F_{\mathrm{X}}^{0}=29.3 \mathrm{~kg}_{\mathrm{cat}} \mathrm{s} \mathrm{mol}{ }^{-1}$. Symbols: experimentally observed values. Lines: calculated based on the net rate of hydrogenation eq 7 and reactor model eq 3 with the preexponential factors from Table 2 and the activation energies and reaction enthalpies from Table 4.

consequence of decreasing (partially hydrogenated) aromatics surface concentrations with the temperature. As a result, the inhibition effects are no longer observed at the highest temperatures. 


\section{SEMK MODEL FOR ALKYL SUBSTITUTED MONOAROMATICS HYDROGENATION}

4.1. Surface Reaction Families and Single-Event Concept. Activation energies and surface reaction enthalpies for benzene hydrogenation have been assessed using DFT methods. ${ }^{17,18,44}$ The number of unsaturated nearest carbon atoms $(m=0,1,2)$ to the carbon atom to which the $\mathrm{H}$ atom is being added was found to be one of the distinctive features between the values obtained for the activation energies and reaction enthalpies of the various $\mathrm{H}$-atom additions. ${ }^{30}$ Here unsaturated carbon atom means the carbon which has a free electron to make a double bond. In addition the activation energy and reaction enthalpy of $\mathrm{H}$-addition elementary steps can also reasonably be assumed to depend on the secondary or tertiary character of the carbon atom $(n=2,3)$ involved, for example, considering the potential steric hindrance in $\mathrm{H}$ addition/ subtraction and changing bond stability with the degree of substitution of the reacting carbon atom. ${ }^{30}$

In addition to this classification of rate coefficients into reaction families based on energetic considerations, within such a reaction family, rate coefficients can still differ from each other because of symmetry effects. This is illustrated in Figure 4, where the first hydrogen atom addition to benzene can occur in 6 equivalent positions whereas the first hydrogen atom addition to toluene has at most 2 equivalent positions.

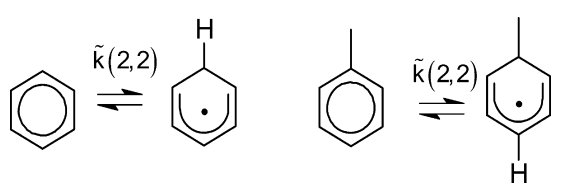

Figure 4. Symmetry effects in hydrogen atom addition.

The symmetry factor in the rate coefficients was factored out via the number of single-events, $n_{\mathrm{e}}$, which is defined as the ratio of symmetry number of the reactant and the activated complex:

$$
n_{\mathrm{e}}=\frac{\sigma_{\text {glob }}^{\mathrm{r}}}{\sigma_{\text {glob }}^{\ddagger}}
$$

The detailed development of the single-event methodology is described elsewhere. ${ }^{45}$ The rate coefficient for an elementary step is written as the product of the number of single-events and the single-event rate coefficient:

$$
k(m, n)=n_{\mathrm{e}} \cdot \tilde{k}(m, n)
$$

A single-event rate coefficient, $\tilde{k}_{\text {hyd }}(m, n)$, and the corresponding equilibrium coefficient, $\tilde{K}(m, n)$, are assigned to each hydrogenation step. Here $m$ represents the saturation state of nearest neighbors $(0,1$, or 2$)$ and $n$ the degree of branching of the reacting carbon atom ( 2 or 3 ). This results in six different reaction families with specific activation energies and reaction enthalpies. The detailed development of the surface reaction families and SEMK model for aromatics hydrogenation is described in our earlier work. ${ }^{30}$

4.2. Reaction Network for Toluene and o-Xylene Hydrogenation. The application of the SEMK methodology for aromatics hydrogenation requires the construction of a detailed reaction network for the selected aromatic model component at the molecular level. Aromatics hydrogenation on Pt catalysts is generally assumed to occur through a HoriutiPolanyi mechanism involving atomic $\mathrm{H}$-addition steps. Com- pared to benzene hydrogenation, the methyl branching of the aromatic ring in toluene and $o$-xylene breaks the symmetry that is present in the aromatic ring. As a result, the number of parallel $\mathrm{H}$ addition pathways is significantly increased: while in the benzene hydrogenation network, 13 components are interconnected through $20 \mathrm{H}$ additions and $20 \mathrm{H}$ abstractions, ${ }^{30}$ for toluene 40 components are interconnected by $104 \mathrm{H}$ additions and $104 \mathrm{H}$ abstractions, see Figure 5, while for $o$-xylene 36 components and $96 \mathrm{H}$ additions and abstractions are involved, see Figure 6. The metal atoms were not included in the species representation during reaction network generation of toluene and $o$-xylene hydrogenation. ${ }^{30}$

The reaction network of toluene and $o$-xylene hydrogenation consists of several consecutive and parallel elementary steps. In the toluene hydrogenation network, 4 partially hydrogenated intermediates can be formed after a single $\mathrm{H}$ addition, 9 after two $\mathrm{H}$ additions, 12 after three $\mathrm{H}$ additions, 9 after four $\mathrm{H}$ additions, and 4 after five additions before, finally methylcycohexane $(\mathrm{MCH})$ is formed, see Figure 5. Similarly, in the case of $o$-xylene hydrogenation, 3, 9, 10, 9, and 3 partially hydrogenated intermediates can be formed after a single, two, three, four, and five $\mathrm{H}$ additions, respectively, before 1,2-dimethylcyclohexane is formed, see Figure 6.

4.3. Kinetic Equations. Unlike in previous LangmuirHinshelwood models ${ }^{13,14,16,18,42,43}$ no dominant reaction path is considered in the SEMK model. This implies that the entire hydrogenation network is considered, including the position in which the hydrogen atoms are being added. No rate-determining step is assumed, either. All $\mathrm{H}$-atom additions and abstractions are considered to be non quasi equilibrated. Reactant chemisorption and product desorption are assumed to be quasi equilibrated. The main assumptions in the SEMK model for substituted aromatics hydrogenation are identical to those in the case of benzene hydrogenation ${ }^{30}$ and are summarized below:

(i) Competitive, dissociative $\mathrm{H}_{2}$ and molecular aromatics chemisorption on identical sites.

(ii) $\mathrm{H}_{2}$, aromatics and cycloalkane chemisorption are quasiequilibrated.

(iii) No dehydrogenated surface species are considered. ${ }^{44}$

(iv) No rate-determining step or dominant reaction path is assumed.

(v) Each reaction step of the network is considered to be reversible.

(vi) The steady state hypothesis is applied for the partially hydrogenated surface intermediates.

(vii) The single-event rate coefficients for atomic $\mathrm{H}$ addition only depend on the number of unsaturated nearest neighbor carbon atoms $(m)$ with respect to the carbon atom involved in the $\mathrm{H}$ addition and branching degree $(n)$ of the reacting carbon atom.

In the SEMK model developed for benzene hydrogenation only the saturation sate of the adjacent carbon atoms to the reacting carbon atom plays a role. In the case of toluene and $o$ xylene hydrogenation, because of the presence of a methyl substituent, the branching degree of the reactive carbon atom may also affect the elementary $\mathrm{H}$-addition kinetics, see Section 4.1.

Each elementary step of the reaction network is considered reversible and potentially contributes to the net production rate. The net production rate of the hydrogenated aromatics in the gas phase is assumed to be equal to the net production rate of the chemisorbed hydrogenated aromatics. For determining the 


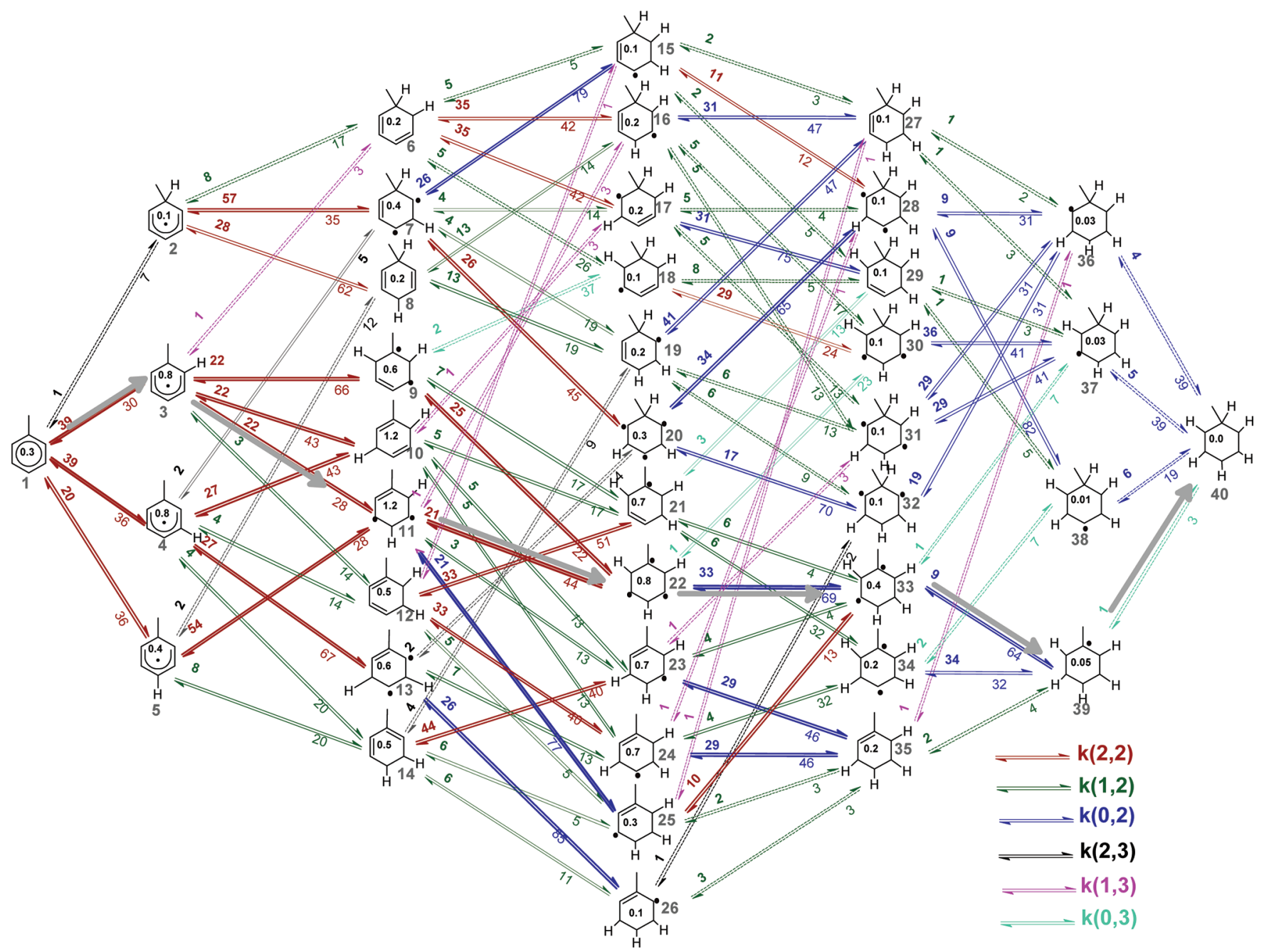

Figure 5. Toluene hydrogenation reaction network indicating the number of partially hydrogenated intermediates on the catalyst surface as well as the rate coefficients with different color and corresponding reaction families involved in the various hydrogen atom addition reactions. Contribution analysis for toluene hydrogenation on Pt $/ \mathrm{ZSM}-22$ at $T=473 \mathrm{~K}, W / F_{\mathrm{T}}^{0}=81.8 \mathrm{~kg} \mathrm{~s} \mathrm{~mol}^{-1} ; p_{\mathrm{t}}=1 \mathrm{MPa} ; p_{\mathrm{T}}^{0}=10 \mathrm{kPa}$, inlet $\gamma_{\mathrm{H} 2 / \mathrm{T}}$ ratio 10 for the simplified model. Numbers above and below the arrows, calculated using eq 4, indicate percentage contributions of the corresponding elementary step toward the overall consumption of the considered species. Numbers indicating hydrogenation steps are in bold. The thickness of the reversible arrows is scaled according to $\log (r)$. Rates below $10^{-4} \mathrm{~mol} \mathrm{~kg}_{\mathrm{cat}}{ }^{-1} \mathrm{~s}^{-1}$ are indicated by dashed arrows. Numbers inside the rings are the calculated percentage distributions between the hydrocarbon species. "Preferred" reaction pathway of toluene hydrogenation on Pt catalyst is shown by full line arrow as per the SEMK model.

latter, the concentrations of all surface intermediates are required. The pseudosteady state hypothesis is applied to determine these concentrations of partially hydrogenated surface intermediates. The net production rate $\left(R_{j}\right)$ of any intermediate $j$ is calculated using eq 7 .

$$
\begin{aligned}
R_{j}= & \sum_{i}\left(r_{i \rightarrow j}^{\mathrm{hyd} / \mathrm{deh}}-r_{j \rightarrow i}^{\mathrm{deh} / \mathrm{hyd}}\right) \\
= & \sum_{i}\left\{n_{e, i \rightarrow j}\left[\tilde{k}_{\mathrm{hyd}}\left(m_{i}, n_{i}\right) C_{\mathrm{H}^{*}}+\tilde{k}_{\mathrm{deh}}\left(m_{i}, n_{i}\right) C_{*}\right] C_{i}\right. \\
& \left.-n_{e, j \rightarrow i}\left[\tilde{k}_{\mathrm{hyd}}\left(m_{j}, n_{j}\right) C_{\mathrm{H}^{*}}+\tilde{k}_{\mathrm{deh}}\left(m_{j}, n_{j}\right) C_{*}\right] C_{j}\right\}
\end{aligned}
$$

In the latter equation, the single-event dehydrogenation rate coefficient $\tilde{k}_{\mathrm{deh}}(m, n)$ is calculated from single-event hydrogenation rate coefficient, $\tilde{k}_{\text {hyd }}(m, n)$ and the corresponding equilibrium coefficient, $\tilde{K}(m, n)$.

4.4. Reduction of Number of Adjustable Model Parameters. The SEMK model for the benzene hydrogenation contains 9 coefficients, each consisting of a pre-exponential factor and an activation energy or a reaction enthalpy. ${ }^{30}$ The extension of the SEMK hydrogenation model toward substituted aromatics such as toluene and $o$-xylene, requires accounting for the addition of hydrogen atoms to tertiary carbon atoms. This doubles the number of single-event rate and equilibrium coefficients. While the experimental data have been acquired separately, the regression analysis for toluene and $o$-xylene hydrogenation was done simultaneously. As a result of the above-discussed considerations, the SEMK model for toluene and $o$-xylene hydrogenation contains 17 coefficients, that is, 6 single-event hydrogenation rate coefficients, 6 single-event (de)-hydrogenation equilibrium coefficients, and 5 chemisorption equilibrium coefficients. The temperature dependence of each parameter doubles the number of adjustable parameters to 34 , which is an excessive number of parameters to be determined accurately based on a single response, that is, the molar outlet flow rate of the hydrogenated aromatic component. Hence, a reduction in the number of adjustable parameters is necessary by using statistical thermodynamics and thermodynamic consistency. 


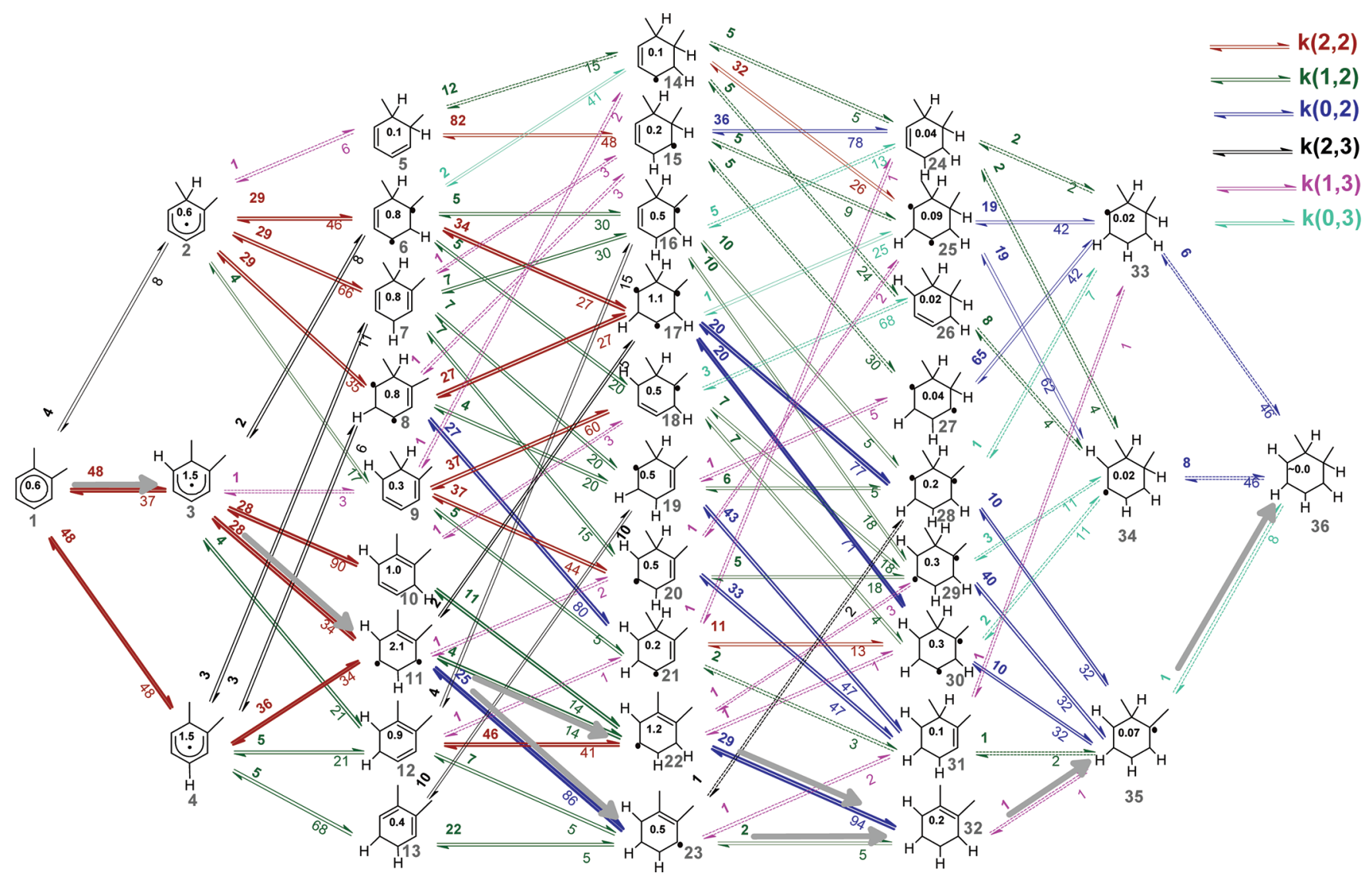

Figure 6. $o$-Xylene hydrogenation reaction network indicating the number of the partially hydrogenated intermediates on the catalyst surface as well as the rate coefficients with different color and corresponding reaction families involved in the various hydrogen atom addition reactions. Contribution analysis for $o$-xylene hydrogenation on Pt $/ \mathrm{ZSM}-22$ at $T=473 \mathrm{~K}, W / F_{\mathrm{X}}^{0}=89.3 \mathrm{~kg} \mathrm{~s} \mathrm{~mol}{ }^{-1} ; p_{\mathrm{t}}=1 \mathrm{MPa} ; p^{0} \mathrm{X}=10 \mathrm{kPa}$, inlet $\gamma_{\mathrm{H} 2 / \mathrm{x}}$ ratio 10 for the simplified model. Numbers above and below the arrows, calculated using eq 4 , indicate percentage contributions of the corresponding elementary step toward the overall consumption of the considered species. Numbers indicating hydrogenation steps are in bold. The thickness of the reversible arrows is scaled according to $\log (r)$. Rates below $10^{-4} \mathrm{~mol} \mathrm{~kg}_{\mathrm{cat}}{ }^{-1} \mathrm{~s}^{-1}$ are indicated by dashed arrows. Numbers inside the rings are the calculated percentage distributions between the hydrocarbon species. "Preferred" reaction pathway of $o$-xylene hydrogenation on Pt catalyst is shown by full line arrow as per the SEMK model.

4.4.1. Statistical Thermodynamics. Analogous to the SEMK model for benzene hydrogenation, all pre-exponential factors of the single-event rate coefficients $\tilde{k}(m, n)$, the single-event equilibrium coefficients $\tilde{K}(m, n)$, and the chemisorption equilibrium coefficients were assessed using transition state theory and statistical thermodynamics. ${ }^{46,47}$ These pre-exponential factors were kept fixed during the model regression to determine the activation energies and reaction enthalpies. As a result, the number of adjustable parameters was reduced from 34 to 17 . The pre-exponential factors of the single-event rate and equilibrium coefficients were assumed to be independent of the carbon atom type considered, that is, identical values were used irrespective of the secondary or tertiary nature of the carbon atom involved in the reaction. The pre-exponential factor calculations were based on physically reasonable assumptions with respect to the mobility of the species involved in the considered elementary steps. Hence, similar mobility is assumed for benzene, toluene, and $o$-xylene. ${ }^{18}$ Regressions have been performed with various sets of pre-exponential factor values which were in the range of physically acceptable values. The selected set of pre-exponential factor values, see Table 2, was that giving rise to the least systematic deviations between experimental observations and model calculations as well as to the physically most significant set of activation energies and reaction enthalpies. This set
Table 2. Values for the Pre-Exponential Factors Used during Regression $^{30}$

$\begin{array}{cccc}K^{0}(m, n)\left(\mathrm{s}^{-1}\right)^{a} & K^{0}(m, n)^{a} & K_{\mathrm{A}}^{0}\left(\mathrm{~Pa}^{-1}\right) & \left.K_{\mathrm{H}_{2}}^{0}\right)\left(\mathrm{Pa}^{-1}\right) \\ 10^{16} & 1 & 10^{-12} & 10^{-11} \\ a_{m}=0,1,2 ; n=2,3 . & & & \end{array}$

corresponded with a significant loss of translational freedom upon toluene and $o$-xylene chemisorption, while the hydrogen mobility on the catalyst surface was higher. More details on the pre-exponential factor calculations and their physical significance are reported in previous work. ${ }^{16,30}$

4.4.2. Thermodynamic Consistency. Thermodynamic consistency can be applied between elementary steps on the catalyst surface as well as for the entire aromatics hydrogenation pathway to establish relationships between model parameters and, hence, further reduce the number of adjustable parameters. ${ }^{30}$ The relationships below are those constructed based on thermodynamic consistency for benzene hydrogenation: ${ }^{30}$

$$
\tilde{K}(1,2) \cdot \tilde{K}(1,2)=\tilde{K}(2,2) \cdot \tilde{K}(0,2)
$$




$$
\left\{\begin{array}{l}
\Delta H(1,2)=\frac{\Delta H(2,2)+\Delta H(0,2)}{2} \\
\Delta S(1,2)=\frac{\Delta S(2,2)+\Delta S(0,2)}{2}
\end{array}\right.
$$

These relationships remain valid for toluene and $o$-xylene hydrogenation as similar pathways exist within the complex reaction network of these two compounds.

The presence of surface intermediates with one or more tertiary carbon atoms brings two additional independent BornHaber cycles with them, see Figure 7. The hydrogenation of 2-

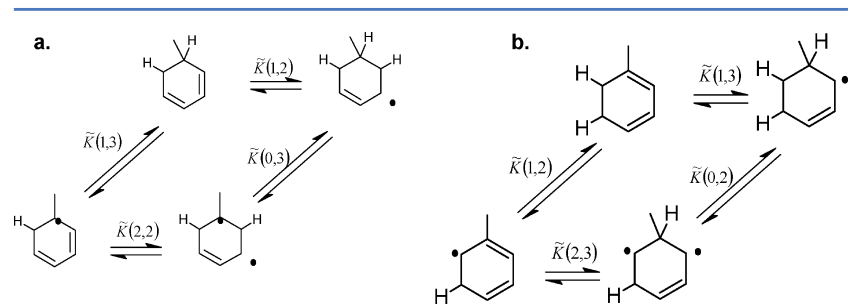

Figure 7. Thermodynamic consistency for hydrogenation of (a) 2hydrotoluene to 1,2,6-trihydrotoluene and (b) 3-hydrotoluene to 1,2,3trihydrotoluene.

hydrotoluene to 1,2,6-trihydrotoluene, see Figure 7a, can occur through two thermodynamically different pathways leading to the following constraints on the corresponding reaction enthalpies and entropies based on the principle of thermodynamic consistency:

$$
\begin{aligned}
& \tilde{K}(1,3) \tilde{K}(1,2)=\tilde{K}(2,2) \tilde{K}(0,3) \\
& \left\{\begin{array}{c}
\Delta H(1,3)+\Delta H(1,2) \\
=\Delta H(2,2)+\Delta H(0,3) \\
\Delta S(1,3)+\Delta S(1,2)=\Delta S(2,2)+\Delta S(0,3)
\end{array}\right.
\end{aligned}
$$

Similarly, the hydrogenation of 3-hydrotoluene to 1,2,3trihydrotoluene, see Figure $7 \mathrm{~b}$, leads to two additional constraints:

$$
\begin{aligned}
& \tilde{K}(1,3) \tilde{K}(1,2)=\tilde{K}(2,3) \tilde{K}(0,2) \\
& \left\{\begin{array}{c}
\Delta H(1,3)+\Delta H(1,2) \\
=\Delta H(2,3)+\Delta H(0,2) \\
\Delta S(1,3)+\Delta S(1,2)=\Delta S(2,3)+\Delta S(0,2)
\end{array}\right.
\end{aligned}
$$

Thermodynamic consistency can also be applied toward the entire catalytic cycle of toluene and $o$-xylene hydrogenation:

$$
\left\{\begin{aligned}
\Delta H_{g, \mathrm{MCH}}= & \Delta H_{\mathrm{T}}+3 \Delta H_{\mathrm{H}_{2}}+\Delta H(0,2) \\
& +4 \Delta H(1,2)+\Delta H(2,3) \\
& -\Delta H_{\mathrm{MCH}} \\
\Delta S_{g, \mathrm{MCH}}= & \Delta S_{\mathrm{T}}+3 \Delta S_{\mathrm{H}_{2}}+\Delta S(0,2) \\
& +4 \Delta S(1,2)+\Delta S(2,3) \\
& -\Delta S_{\mathrm{MCH}}
\end{aligned}\right.
$$

$$
\left\{\begin{aligned}
\Delta H_{g, \mathrm{DMCH}}= & \Delta H_{x}+3 \Delta H_{\mathrm{H}_{2}}+\Delta H(0,2) \\
& +3 \Delta H(1,2)+\Delta H(1,3) \\
& +\Delta H(2,3)-\Delta H_{\mathrm{DMCH}} \\
\Delta S_{g, \mathrm{DMCH}}= & \Delta S_{x}+3 \Delta S_{\mathrm{H}_{2}}+\Delta S(0,2) \\
& +3 \Delta S(1,2)+\Delta S(1,3) \\
& +\Delta S(2,3)-\Delta S_{\mathrm{DMCH}}
\end{aligned}\right.
$$

From eqs 14 and 15, values for the chemisorption enthalpies and entropies of methylcyclohexane and 1,2-dimethylcyclohexane have been determined.

It can be noted that, because of the thermodynamic consistency relationships eqs 9, 11, 13, the relationships eqs 14 and 15 are independent of the actual pathway followed on the surface. As a result, the number to kinetic parameters to be estimated is further reduced from 17 to 13 . Hence 6 activation energies $\left[E_{\mathrm{a}}(0,2), E_{\mathrm{a}}(1,2), E_{\mathrm{a}}(2,2), E_{\mathrm{a}}(0,3), E_{\mathrm{a}}(1,3), E_{\mathrm{a}}(2,3)\right], 3$ reaction enthalpies $[\Delta H(0,2), \Delta H(2,2), \Delta H(0,3)]$ and 3 chemisorption enthalpies $\left[\Delta H_{\mathrm{T}}, \Delta H_{\mathrm{X}}, \Delta H_{\mathrm{H} 2}\right]$ are to be estimated in the SEMK model for aromatics hydrogenation.

4.4.3. Single-Event Methodology. The kinetic and thermodynamic parameters in the SEMK aromatics hydrogenation model related to secondary carbon atoms have been estimated as part of previous work on benzene hydrogenation on a $\mathrm{Pt}$ catalyst. $^{30}$ Relying on the single-event concept and the corresponding feed independence of the model parameters, the activation energies and reaction enthalpies for $\mathrm{H}$ addition to secondary carbon atoms as well as chemisorption enthalpy of hydrogen, obtained from selected SEMK model of benzene hydrogenation, are used without further adjustments in the regression of the toluene and $o$-xylene hydrogenation data set. As a result, only the activation energies and surface reaction enthalpies of the $\mathrm{H}$ addition to tertiary carbon atoms and the chemisorption enthalpies of toluene and $o$-xylene are to be determined from regression. Hence, the ultimate number of adjustable kinetic parameters in the extended SEMK model for substituted aromatics is limited to $6 ; 3$ activation energies $\left[E_{\mathrm{a}}(0,3), E_{\mathrm{a}}(1,3), E_{\mathrm{a}}(2,3)\right], 1$ reaction enthalpy $[\Delta H(0,3)]$ and 2 chemisorption enthalpies $\left[\Delta H_{\mathrm{T}}, \Delta H_{\mathrm{X}}\right]$.

\section{REGRESSION RESULTS AND DISCUSSION}

Nonisothermal regression analysis was performed for toluene and $o$-xylene hydrogenation data simultaneously. As a reference model all 6 adjustable parameters have been estimated without further constraints. The obtained results are discussed in Section 5.1 and have suggested guidelines for further model simplification which are subsequently addressed in Section 5.2.

5.1. Reference Model: 6 Adjustable Parameters. In this reference model all 6 remaining adjustable parameters mentioned in Section 4.4.3 are estimated simultaneously without further constraints using the toluene and $o$-xylene hydrogenation data sets. The agreement that can be reached between the experimentally observed and model calculated methylcyclohexane and 1,2-dimethylcyclohexane molar outlet flow rates is shown in the parity diagrams in Figure 8. An F value for the global significance of the regression amounting to 352 was obtained, indicating that the regression was indeed significant. The parameter estimates along with their individual $95 \%$ confidence intervals are reported in Table 3 and are in agreement with literature reported values. ${ }^{14,16,18,48-50}$ The activation energies are in the range of 55 to $70 \mathrm{~kJ} \mathrm{~mol}^{-1}$ for $\mathrm{H}$ addition to a secondary or 

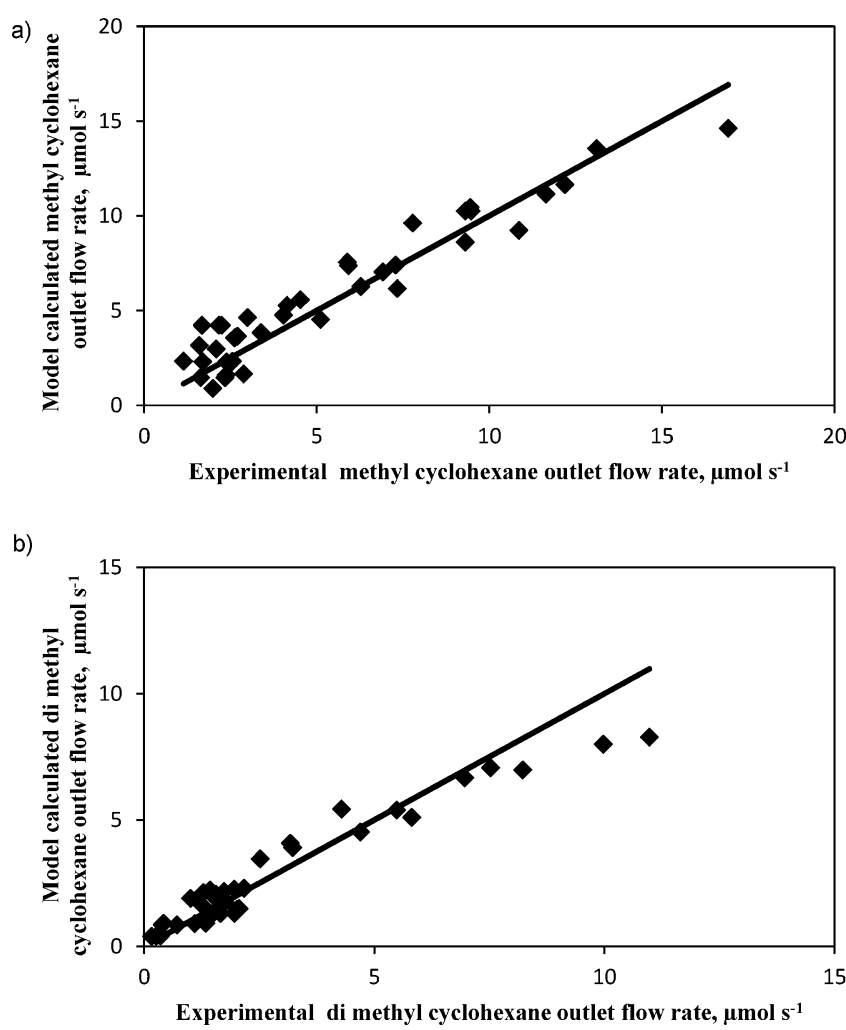

Figure 8. Parity diagram of experimental vs calculated molar outlet flow rate of (a) methylcyclohexane and (b) 1,2-dimethylcyclohexane using the reference model; line: bisector indicating perfect agreement, model calculated after non isothermal regression with the preexponential factors from Table 2 and the activation energies and reaction enthalpies from Table 3 and the net rate of hydrogenation eq 7 and reactor model eq 3 .

Table 3. Parameter Values $\left(\mathrm{kJ} \mathrm{mol}^{-1}\right)$ for the SEMK Model for Aromatics Hydrogenation on Pt Catalyst in the Reference Model $^{a}$

$\begin{array}{ccccccc}E_{\mathrm{a}}(0,2) & E_{\mathrm{a}}(1,2) & E_{\mathrm{a}}(2,2) & E_{\mathrm{a}}(0,3) & E_{\mathrm{a}}(1,3) & E_{\mathrm{a}}(2,3) \\ 57.5^{b} & 65.1^{b} & 57.5^{b} & 68.8 \pm 11.5 & 72.7 \pm 64 & 70.3 \pm 58 \\ \Delta H(0,2) & \Delta H(1,2) & \Delta H(2,2) & \Delta H(0,3) & \Delta H(1,3) & \Delta H(2,3) \\ 7.9^{b} & 4.5^{b} & 1.2^{b} & 10.9 \pm 1.5 & 7.6^{c} & 4.2^{c} \\ \Delta H_{\mathrm{T}} & & \Delta H_{\mathrm{MCH}} & \Delta H_{\mathrm{X}} & \Delta H_{\mathrm{DMCH}} & \Delta H_{\mathrm{H} 2} \\ -54.6 \pm<0.5 & 8.4^{c} & -56.4 \pm<0.5 & 0.6^{c} & -59.4^{b}\end{array}$

${ }^{a}$ Values with confidence intervals are obtained by regression using the net rate of hydrogenation eq 7 and reactor model eq $3 .{ }^{b}$ Obtained from the selected SEMK model of benzene hydrogenation on $\mathrm{Pt}$ catalyst. ${ }^{30}{ }^{c}$ Calculated using thermodynamic consistency.

a tertiary aromatic carbon atom, see Table 3 . Lin and Vannice estimated apparent activation energies in the range of 50-60 kJ $\mathrm{mol}^{-1}$ for benzene, toluene and xylene hydrogenation on supported Pt catalyst, which leads to even higher true activation energies considering a typical aromatics chemisorption enthalpy of $60 \mathrm{~kJ} \mathrm{~mol}^{-1}$. $^{14}$ Thybaut et al. estimated a true activation energy in the range of 40 to $50 \mathrm{~kJ} \mathrm{~mol}^{-1}$ for toluene hydrogenation on the same Pt catalyst which is used in this study. ${ }^{16}$ The activation energies for $\mathrm{H}$ addition to a tertiary carbon atom are systematically higher than those for $\mathrm{H}$ addition to a secondary carbon atom. This can be related to the steric hindrance caused by the methyl group. Given the identical pre-exponential factors that were used, the $\mathrm{H}$ additions to tertiary carbon atoms have a lower rate coefficient than those to secondary carbon atoms.

It is to be noted that $E_{\mathrm{a}}(1,3)$ and $E_{\mathrm{a}}(2,3)$ have a much wider confidence intervals compared to $E_{\mathrm{a}}(0,3)$. It indicates that the $\mathrm{H}$ addition to a tertiary aromatic carbon atom with saturated neighboring carbon atoms is kinetically more relevant than the $\mathrm{H}$ additions to a tertiary aromatic carbon atom with at least one unsaturated neighboring carbon atom. Moreover, $E_{\mathrm{a}}(0,3)$ is lower than $E_{\mathrm{a}}(1,3)$ and $E_{\mathrm{a}}(2,3)$, and, hence, the hydrogen atom will be preferentially added at a tertiary carbon after $\mathrm{H}$ additions have occurred on the neighboring carbon atoms. This indicates that a dominant reaction pathway, if any, will have the $\mathrm{H}$ addition to a tertiary carbon atom near the end of the hydrogenation sequence.

Surface reaction enthalpies were estimated significantly although the values are rather close to zero. They indicate a slight endothermicity of the hydrogenation reactions on the catalyst surface which agrees with quantum chemically obtained values and with the conclusion that the aromaticity of the reactant is lost upon chemisoption on Pt catalyst surface. ${ }^{16,18}$

Practically no difference in values was noticeable for the estimated toluene and $o$-xylene chemisorption enthalpies, that is, -54.6 versus $-56.4 \mathrm{~kJ} \mathrm{~mol}^{-1}$. Lin and Vannice ${ }^{14}$ found chemisorption enthalpies in the range of -50 to $-70 \mathrm{~kJ} \mathrm{~mol}^{-1}$ for toluene hydrogenation on supported Pt catalyst, while Thybaut et al. ${ }^{16}$ estimated a value of $-70 \mathrm{~kJ} \mathrm{~mol}^{-1}$ for toluene chemisorption on Pt. Moreover, with a value of $-56 \mathrm{~kJ} \mathrm{~mol}^{-1}$ estimated with the SEMK model, ${ }^{30}$ also the benzene chemisorption enthalpy is of the same order of magnitude and, hence, the differences between the aromatic chemisorption enthalpies are insufficient to explain the differences in hydrogenation kinetics of the various components. It seems from these values that aromatic chemisorption is mainly governed by the loss of the aromaticity of the ring, regardless its substitution degree. As a result, according to the SEMK model, differences in hydrogenation rates between the investigated monoaromatic components are primarily due to differences in $\mathrm{H}$ addition rate coefficients rather than in chemisorption strength.

As calculated from thermodynamic consistency, the chemisorption of the hydrogenated products is almost thermoneutral to even endothermic. This is in agreement with a rapid, irreversible desorption from the catalyst surface as it was also concluded for the benzene hydrogenation data. ${ }^{30}$

5.2. Simplified Model: 4 Adjustable Parameters. As evident from the results of the unconstrained regression in the reference model, the difference between the activation energies for $\mathrm{H}$ addition to a secondary or a tertiary carbon atom seems practically independent from the number of unsaturated neighboring carbon atoms. As a result, in the present paragraph, the performance of a simplified model is investigated in which a identical increment between activation energies for $\mathrm{H}$ addition to secondary and tertiary carbon atoms, regardless of the number of unsaturated nearest neighbor atoms $\left[\Delta E_{\mathrm{a}}^{\text {ter-sec }}=E_{\mathrm{a}}(0,3)-\right.$ $\left.E_{\mathrm{a}}(0,2)=E_{\mathrm{a}}(1,3)-E_{\mathrm{a}}(1,2)=E_{\mathrm{a}}(2,3)-E_{\mathrm{a}}(2,2)\right]$, is assumed between the corresponding activation energies. This reduces the number of adjustable parameters in the simultaneous regression of toluene and $o$-xylene hydrogenation data to 4 .

An $\mathrm{F}$ value amounting to 517 was obtained for the global significance of the regression. The parity diagrams for outlet flow rate of methylcyclohexane and 1,2-dimethylcyclohexane are given in Figure 9 and indicate that also the simplified model is able to adequately describe the toluene and $o$-xylene hydro- 


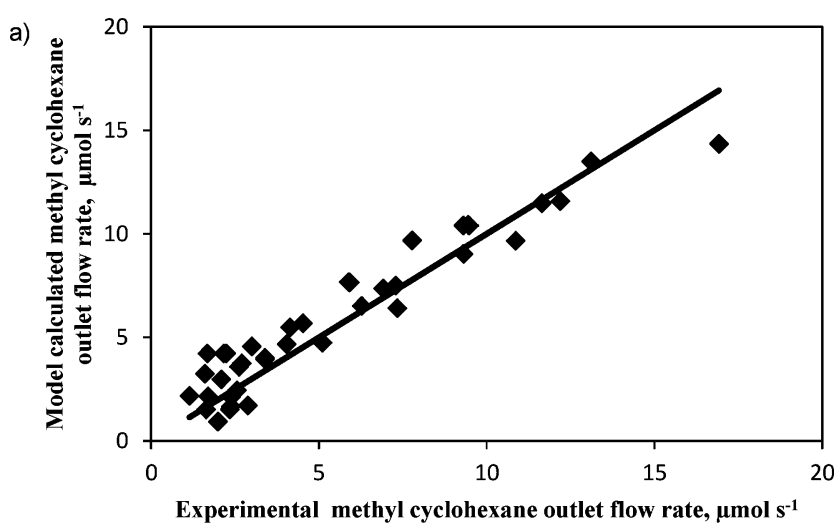

b)

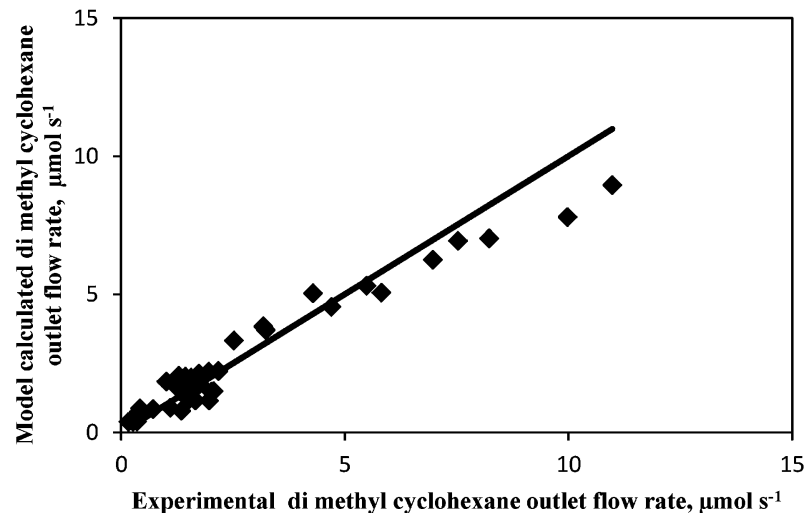

Figure 9. Parity diagram of experimental vs calculated molar outlet flow rate of (a) methylcyclohexane and (b) 1,2-dimethylcyclohexane using the simplified model; line: bisector indicating perfect agreement, $\nabla$ : model calculated after non isothermal regression with the preexponential factors from Table 2 and the activation energies and reaction enthalpies from Table 4 and the net rate of hydrogenation eq 7 and reactor model eq 3 .

genation kinetics on $\mathrm{Pt}$. An overview of the estimated parameter values is presented in Table 4.

Table 4. Values $\left(\mathrm{kJ} \mathrm{mol}^{-1}\right)$ for the SEMK Model for Aromatics Hydrogenation on Pt Catalyst for the Simplified Model ${ }^{a}$

\begin{tabular}{|c|c|c|c|c|c|}
\hline$E_{\mathrm{a}}(0,2)$ & $E_{\mathrm{a}}(1,2)$ & $E_{\mathrm{a}}(2,2)$ & \multicolumn{2}{|c|}{$\Delta E_{\mathrm{a}}^{\text {ter-sec }}$} & \\
\hline $57.5^{b}$ & $65.1^{b}$ & $57.5^{b}$ & \multicolumn{2}{|c|}{$10.5 \pm 1.6$} & \\
\hline$\Delta H(0,2)$ & $\Delta H(1,2)$ & $\Delta H(2,2)$ & $\Delta H(0,3)$ & $\Delta H(1,3)$ & $\Delta H(2,3)$ \\
\hline $7.9^{b}$ & $4.5^{b}$ & $1.2^{b}$ & $11.5 \pm 0.8$ & $8.2^{c}$ & $4.2^{c}$ \\
\hline$\Delta H_{\mathrm{T}}$ & \multicolumn{2}{|c|}{$\Delta H_{\mathrm{MCH}}$} & $\Delta H_{\mathrm{X}}$ & $\Delta H_{\mathrm{DMCH}}$ & $\Delta H_{\mathrm{H} 2}$ \\
\hline$-55.7 \pm$ & \multicolumn{2}{|c|}{$7.3^{c}$} & $\pm<0.5$ & $0.1^{c}$ & $-59.4^{b}$ \\
\hline
\end{tabular}

${ }^{a}$ Values with $95 \%$ confidence intervals are obtained by regression using the net rate of hydrogenation eq 7 and reactor model eq 3 .

${ }^{b}$ Obtained from the selected SEMK model of benzene hydrogenation on Pt catalyst. ${ }^{30}$ Calculated using thermodynamic consistency.

The estimate for the increment between the activation energies for $\mathrm{H}$ addition to secondary and tertiary carbon atoms regardless the amounts of unsaturated neighbor atoms amounts to $10.5 \mathrm{~kJ} \mathrm{~mol}^{-1}$, the latter ones having the higher activation energies. These statistically significantly higher activation energies for $\mathrm{H}$ addition to tertiary carbon atoms is in line with the values estimated in the earlier reference model, see section 5.1, in which this has been related to steric effects. Also surface reaction enthalpies for $\mathrm{H}$ addition to tertiary carbon atoms are systematically higher than those for secondary carbon atoms, that is, by about $3.5 \mathrm{~kJ} \mathrm{~mol}^{-1}$. With estimates for the toluene and $o$ xylene chemisorption enthalpies amounting to -55.7 and -56.9 $\mathrm{kJ} \mathrm{mol}^{-1}$, the aromatic chemisorption enthalpies remain in the same order of magnitude. The overall trends in model parameter values obtained in this simplified model, see Table 4, agree with those obtained in the reference model, see Table 3.

5.3. Model Selection and Assessment. In both the reference and the simplified model, modeling results are obtained that are numerically very similar to each other and, hence, also have a very similar physical interpretation. Differences between the parity diagrams obtained in the reference model, see Figure 8, and the simplified model, see Figure 9, are minor and lead to a practically indistinguishable graphical representation. The constant increment that was estimated in the simplified model had a narrow confidence interval, whereas $E_{\mathrm{a}}(1,3)$ and $E_{\mathrm{a}}(2,3)$ were having very wide confidence intervals in the reference model. The statistical performance of the reference and the simplified model is further compared in Table 5. The

Table 5. Summary of Results of Non-Isothermal Model Regression for Toluene and $o$-Xylene Hydrogenation over Pt/ ZSM-22 Catalyst Using Experimental Data

$\begin{array}{lcc} & \text { reference model }^{a} & \text { simplified model }^{b} \\ \text { number of parameters } & 6 & 4 \\ \text { F value } & 352 & 517 \\ \text { residual sum of squares, } \text { mol }^{2} \mathrm{~s}^{-2} & 75 \times 10^{-6} & 80 \times 10^{-6} \\ { }^{a} \text { Unconstrained regression. }^{b} \Delta E_{\mathrm{a}}{ }^{\text {ter-sec }}=E_{\mathrm{a}}(0,3)-E_{\mathrm{a}}(0,2)=E_{\mathrm{a}}(1,3)- \\ E_{\mathrm{a}}(1,2)=E_{\mathrm{a}}(2,3)-E_{\mathrm{a}}(2,2) .\end{array}$

residual sum of squares obtained with the simplified model with 4 adjustable parameters is only marginally higher than that obtained with the reference model in which 6 parameters were estimated. It is confirmed by the $\mathrm{F}$ value for the global significance of the regression obtained for both models that the lower number of parameters in the simplified model outweighs this minor increase in residual sum of squares. An almost 50\% increase of this $\mathrm{F}$ value for the simplified model compared to the reference model expresses a preference for the simplified model on a statistical basis. The model calculated conversions as a function of the temperature and hydrogen partial pressure indicate the overall model adequacy in reproducing the experimental behavior, see Figures 1, 2, and 3.

The fractional surface coverages of all partially hydrogenated aromatic species and hydrogen are calculated using the entire reaction network for toluene and $o$-xylene hydrogenation. For toluene hydrogenation, at typical reaction conditions, that is, $T=$ $448 \mathrm{~K}, p_{\mathrm{T}}^{0}=20 \mathrm{kPa}, p_{\mathrm{H}}^{0}=100 \mathrm{kPa}$, approximately $50 \%$ of the surface is covered with chemisorbed hydrocarbons species and around $40 \%$ of the catalyst surface is occupied by hydrogen atoms, the remaining $10 \%$ being free, see Figure 10a. While for $o$ xylene hydrogenation, at typical reaction condition, that is, $T=$ $448 \mathrm{~K}, p^{0}{ }_{\mathrm{X}}=20 \mathrm{kPa}, p_{\mathrm{H}}^{0}=100 \mathrm{kPa}$, approximately $60 \%$ of the surface is covered with chemisorbed hydrocarbons and around $30 \%$ of the catalyst surface is occupied by hydrogen atoms, the remaining $10 \%$ being free, see Figure $10 \mathrm{~b}$. This is in good agreement with previously obtained values. ${ }^{16,18,30}$ The fraction of the surface occupied by hydrocarbons sharply decreases upon a temperature increase. The opposite effect is observed for the surface concentrations of hydrogen and for the free active sites. These evolutions in surface coverage explain the maximum observed in hydrogenation conversion as a function of the 

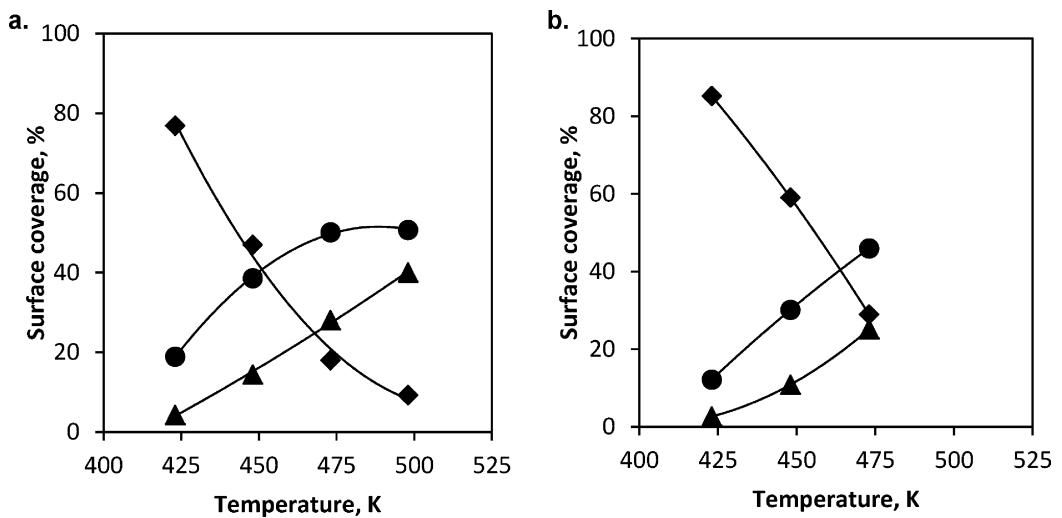

Figure 10. Effect of temperature on the surface concentrations of hydrocarbons $(\bullet)$, hydrogen $(\bullet)$, and free sites $(\boldsymbol{\Delta})$. Calculated based on the net rate of hydrogenation eq 7 and reactor model eq 3 with the pre-exponential factors from Table 2 and the activation energies and enthalpies from Table 4. [(a.) Toluene hydrogenation: $p_{\mathrm{t}}=1 \mathrm{MPa}, p_{\mathrm{T}}^{0}=20 \mathrm{kPa}$, inlet $\gamma_{\mathrm{H} 2 / \mathrm{T}}$ ratio $5 ; W / F_{\mathrm{T}}^{0}=81.8 \mathrm{~kg}_{\mathrm{cat}} \mathrm{s} \mathrm{mol}{ }^{-1}$; (b.) $o$-xylene hydrogenation: $p_{\mathrm{t}}=1 \mathrm{MPa}, p_{\mathrm{X}}^{0}=20$ $\mathrm{kPa}$; inlet $\gamma_{\mathrm{H} 2 / \mathrm{X}}$ ratio 5; $W / F_{\mathrm{X}}^{0}=89.3 \mathrm{~kg}_{\mathrm{cat}} \mathrm{s} \mathrm{mol}^{-1}$.

temperature. ${ }^{18,51,52}$ Such a maximum was also observed in the present work, see Figure 1 in section 3. From a certain temperature onward, that is, about $450 \mathrm{~K}$, the increase in the rate coefficient is overcompensated by the decrease in hydrocarbon surface concentration.

5.4. Reaction Path Analysis. The relative importance of the various $\mathrm{H}$ addition reactions has been assessed via a contribution analysis based on initial rates of disappearance. Such a contribution analysis allows achieving a better insight in the surface reaction mechanism as well as the determination of a potential, "preferred" reaction pathway. Figures 5 and 6 present the corresponding analyses at $473 \mathrm{~K}$ in pictorial form showing all the surface elementary steps involved in saturation product formation from toluene and $o$-xylene respectively according to the selected model where an identical increment between activation energies for $\mathrm{H}$ additions to secondary and tertiary carbon atoms was assumed, regardless of the number of unsaturated nearest neighbor atoms. Numbers written above and below of arrows indicate percentage contributions of the corresponding elementary step toward the overall consumption of the considered species, calculated using eq 4 , at $16 \%$ toluene conversion and $10 \% o$-xylene conversion. The thickness of the arrows corresponds to the magnitude of the reaction rates scaled according to $\log (r)$. Rates below $10^{-4} \mathrm{~mol} \mathrm{~kg}_{\text {cat }}^{-1} \mathrm{~s}^{-1}$ are indicated by dashed arrows.

The calculated percentage distribution between the hydrocarbon species on a Pt surface at $473 \mathrm{~K}, 1 \mathrm{MPa}$ total pressure and $10 \mathrm{kPa}$ inlet aromatic partial pressure obtained from the model regression in case of toluene and $o$-xylene is also given Figure 5 and Figure 6 respectively. At this condition, it was calculated that $13.5 \%$ of the surface is covered by hydrocarbon species, $56.2 \%$ by hydrogen and that the rest is free. In case of $o$-xylene hydrogenation, at $473 \mathrm{~K}$, it was calculated that $17.8 \%$ of the surface is covered by hydrocarbon species, $53.6 \%$ by hydrogen, and that the rest is free. The percentage distributions of $13.5 \%$ and $17.8 \%$ hydrocarbon species are written inside the ring in Figure 5 and Figure 6 respectively. The surface concentrations of methylcyclohexane and dimethylcyclohexane are negligible because of its low chemisorption coefficient.

5.4.1. Toluene Hydrogenation Network. Figure 5 presents the contribution analysis for toluene hydrogenation on a $\mathrm{Pt}$ catalyst with the selected model. The first $\mathrm{H}$ addition to toluene is mainly occurring via intermediate 3 and 4 where hydrogen is added in the ortho and meta position with respect to the methyl substituent, each intermediate accounting for 39\% of the toluene disappearance. Because $36 \%$ of intermediate 4 will be dehydrogenated back into toluene rather than further hydrogenated to methylcyclohexane, while this is only limited to $30 \%$ of intermediate 3 , the latter will be the "preferred" intermediate after first $\mathrm{H}$ addition. The second $\mathrm{H}$ addition mainly occurs in the meta and para position with respect to first $\mathrm{H}$ addition through intermediates 9,10 , and 11 . From the latter, intermediate 11 is the one which undergoes the least reverse dehydrogenation, that is, $56 \%$ versus $66 \%$ and even $86 \%$ for intermediates 9 and 10 and, hence, can be considered as the "preferred" intermediate. Moreover, intermediate 11 has the most considerable concentration (1.2\%) among the intermediates formed after two $\mathrm{H}$ additions to toluene. The addition of the third hydrogen to intermediate 11 mainly leads to intermediates 22 and 25 . The latter intermediate experiences severe reverse dehydrogenation, amounting to $87 \%$ of its consumption, while $34 \%$ of the former is further hydrogenating and, hence, intermediate 22 can be clearly be denoted as the "preferred" intermediate after three $\mathrm{H}$ additions. It also has the higher concentration (0.8\%) among the intermediates formed after three $\mathrm{H}$ additions of toluene. The fourth $\mathrm{H}$ addition to intermediate 22 can occur only in two distinct positions, that is, one on the tertiary carbon atom leading to intermediate 30 and another one on a secondary carbon atom leading to intermediate 33. Given the higher activation energy for $\mathrm{H}$ addition to a tertiary carbon atom compared to a secondary carbon atom, intermediate 33 is clearly the preferred intermediate after the fourth $\mathrm{H}$ addition. Similarly, intermediate 39 is the preferred intermediate over intermediate 36 after the fifth $\mathrm{H}$ addition, despite the fact that it is undergoing more pronounced dehydrogenation rather than hydrogenation. Moreover, intermediates 33 and 39 have concentrations $0.4 \%$ and $0.05 \%$, respectively, and, hence, are the most abundant surface intermediates to which 4 and 5 hydrogen atoms have been added. Given the identical single-event rate coefficients along the above determined pathway, the lower concentrations of the species to which more $\mathrm{H}$ atoms have been added are indicative of the potentially rate-determining character of the $\mathrm{H}$ atom additions in which they are involved. This is even more pronounced for the final hydrogen addition step, which is starting from intermediate 39 , that is, the one with the lowest concentration in the determined pathway and which is having the highest activation energy, because of the tertiary character of the carbon atom involved. These findings are in line with the discussion of the 
experimental results as made in Section 3 and with the previously, quantum chemically obtained conclusion by Saeys et al. $^{18}$ in their first-principle based kinetic model for the hydrogenation of toluene. Hence the most preferable surface reaction route will be $1-3-11-22-33-39-40$ in case of toluene hydrogenation as shown by the full thick arrow in Figure 5. The identified dominant reaction pathway also passes via the most abundant surface species. The above discussion and interpretation of the contribution analysis is in line with the $\mathrm{H}$ addition predominantly in meta position, as was also observed in benzene hydrogenation. ${ }^{30}$

The simulation of the inhibitory effect at the lowest temperatures has further been assessed at a temperature of 423 $\mathrm{K}$, a total pressure of $1 \mathrm{MPa}$, a hydrogen inlet partial pressure of $100 \mathrm{kPa}$, and a space time $81.8 \mathrm{~kg}_{\text {cat }} \mathrm{s} \mathrm{mol}^{-1}$ using the SEMK model. It was found that increasing the inlet partial pressure of toluene from 10 to $20 \mathrm{kPa}$, the surface coverage of hydrocarbon species increases from 54 to $76.9 \%$ and the hydrogen surface coverage decreases from 30 to $18.9 \%$. As a result the conversion decreases from 13.3 to $7.3 \%$. The corresponding, simulated partial reaction order with respect to hydrocarbon species amounted to -0.15 , which corresponds well with that reported previously ${ }^{16}$ and discussed in Section 3. When increasing the hydrogen inlet partial pressure from 100 to $200 \mathrm{kPa}$ at a toluene inlet partial pressure of $20 \mathrm{kPa}$, the hydrogen surface coverage increased from 18.9 to $32.0 \%$ while the hydrocarbon surface coverage decreased from 76.9 to $67.0 \%$. As a result the overall conversion increased from 7.3 to $16.7 \%$, corresponding with a hydrogen partial reaction order of 0.7 , which, again is in nice agreement with previously reported values ${ }^{16}$ as well as those discussed in Section 3.

5.4.2. o-Xylene Hydrogenation Network. A similar contribution analysis as for toluene hydrogenation has also been performed for $o$-xylene hydrogenation to dimethylcyclohexane, see Figure 6. In this case, the first $\mathrm{H}$ addition is mainly going via intermediates 3 and 4 having an equal surface concentration of $1.5 \%$, that is, via an addition to a secondary carbon atom. As the latter intermediate is rather undergoing dehydrogenation than hydrogenation, intermediate 3 is the "preferred" forward elementary step in the hydrogenation sequence. Intermediates 10 and 11 are mainly formed after the second $\mathrm{H}$ addition to intermediate 3 . However, $90 \%$ of intermediate 10 is rather undergoing dehydrogenation than hydrogenation, while $32 \%$ of intermediate 11 is further hydrogenating. Moreover, intermediate 11 has the higher concentration $(2.1 \%)$ among the intermediates formed after two $\mathrm{H}$ additions of $o$-xylene. Hence, intermediate 11 is considered as the "preferred" intermediate in the hydrogenation sequence. The addition of a third hydrogen atom to intermediate 11 leads to intermediate 23 , that is, $25 \%$ compared to $2 \%$ and $1 \%$ to intermediates 17 and 20 , clearly indicating intermediate 23 as the "preferred" one after the third $\mathrm{H}$ addition. Although intermediate 23 is rather undergoing reverse dehydrogenation than forward hydrogenation, it can undergo $\mathrm{H}$ addition on one of its tertiary carbon atoms leading to intermediates 28 or 31 or on the last unsaturated secondary carbon atom leading to intermediate 32 . Since the latter possibility has the lowest activation energy and, hence, the highest rate coefficient, this will be the preferred one for the fourth $\mathrm{H}$ addition. It can also be noted that once intermediate 11 undergoes hydrogenation to intermediate 22, although its contribution is limited to $4 \%$ only, it finds a "preferred" pathway to form intermediate 32 after the fourth hydrogenation. Hence this pathway can be considered as an alternative "preferred" hydrogenation pathway, certainly if it is realized that intermediate 22 has the higher concentration (1.2\%) among the intermediates formed after three $\mathrm{H}$ additions to $o$-xylene. Because of symmetry reasons, a unique pathway remains for the addition of the fifth and the sixth $\mathrm{H}$ addition to intermediates 32 and 35. Because they both involve a tertiary carbon atom, these $\mathrm{H}$ additions have the lowest absolute rates in the hydrogenation sequence and, hence, have a determining character on the overall rate. The most preferable surface reaction route as identified above is $1-3-11-22$ \& 23-32-35-36 for $o$-xylene hydrogenation. The so-called "meta $\mathrm{H}$-addition pathway" is clearly identified as the "preferred" reaction pathway at the beginning of the hydrogenation sequence, followed by $\mathrm{H}$ addition to secondary carbon atoms and finally to the tertiary carbon atoms of the ring in the $o$-xylene hydrogenation on a Pt catalyst according to the SEMK model.

Similar to the case of toluene hydrogenation, also for $o$-xylene hydrogenation the inhibitory effect at the lower temperatures has been further assessed at $423 \mathrm{~K}$, a total pressure $1 \mathrm{MPa}$, an inlet hydrogen partial pressure $100 \mathrm{kPa}$, and a space time $89.3 \mathrm{~kg}_{\mathrm{cat}} \mathrm{s}$ $\mathrm{mol}^{-1}$. It was found that increasing the inlet partial pressure of $o$ xylene from 10 to $20 \mathrm{kPa}$, the surface coverage of hydrocarbon species increases from 42 to $58 \%$ but the hydrogen surface coverage decreases from 42.8 to $29 \%$. As a result the conversion decreases with increasing inlet $o$-xylene partial pressure from 10.7 to $9.5 \%$. The corresponding, simulated partial reaction order with respect to hydrocarbon species amounted to -0.1 , which corresponds well with the partial reaction orders discussed in Section 3. When increasing the hydrogen inlet partial pressure from 50 to $100 \mathrm{kPa}$ at an $o$-xylene inlet partial pressure of $10 \mathrm{kPa}$, the hydrogen surface coverage increased from 5 to $14 \%$ while the hydrocarbon surface coverage decreased from 73 to $71 \%$. As a result the $o$-xylene hydrogenation conversion increased from 2.7 to $10.7 \%$, corresponding with a hydrogen partial reaction order amounting to 1.5 which is in good agreement with the observed values around 2 .

\section{CONCLUSIONS}

The SEMK methodology has been successfully extended from benzene hydrogenation toward the hydrogenation of mono- and di- substituted aromatics compounds on a Pt catalyst. The judicious definition of the reaction families has allowed the adequate description of the experimental data using a limited number of adjustable parameters. The fundamental nature of the SEMK model has ensured the applicability of the kinetic and thermodynamic parameters, determined from benzene hydrogenation, to the substituted aromatics, for example, toluene and $o$-xylene hydrogenation. On the basis of a statistical analysis while simultaneously accounting for the physical significance of the individual parameter estimates and the kinetic model as a whole, a simplified model with a constant increment between the activation energies for $\mathrm{H}$ addition to secondary and tertiary carbon atoms, irrespective of the number of unsaturated neighboring carbon atoms, was retained. $\mathrm{H}$ additions to secondary carbon atoms are faster than to tertiary carbon atoms. Steric hindrance results in a higher activation energy for $\mathrm{H}$ addition to a tertiary carbon atom compared to a secondary carbon atom. The presence of a methyl substituent on an aromatic ring only has a minor effect on the chemisorption enthalpies of the corresponding component. As a result, differences in aromatics hydrogenation behavior between alkyl substituted monoaromatics compounds are mainly governed by differences in $\mathrm{H}$-addition kinetics rather than by chemisorption 
thermodynamics. A differential contribution analysis of the various elementary steps to the product formation illustrates how the simplified model simulates that hydrogenation first occurs at secondary carbon atoms following a "meta $\mathrm{H}$-addition pathway" prior to the hydrogenation of the tertiary carbon atoms at the end of the hydrogenation sequence. A rate-determining step, if any, occurs near the end of the hydrogenation reaction mechanism. Experimentally observed inhibition effects at lower temperatures are adequately reproduced by the model and explained by high hydrocarbon surface coverages. With increasing temperature, these inhibition effects disappear as the hydrocarbon surface coverages are decreasing.

\section{AUTHOR INFORMATION}

\section{Corresponding Author}

*E-mail: Joris.Thybaut@UGent.be. Fax: +32 (0)9 2644999.

\section{Funding}

This work was undertaken in the framework of a bilateral collaboration between UGent-LCT and BP. This work was also supported by the Interuniversity Attraction Poles ProgrammeBelgian State-Belgian Science Policy and the Long Term Structural Methusalem Funding by the Flemish Government.

\section{Notes}

The authors declare no competing financial interest.

\section{NOMENCLATURE}

* $\quad$ active site on catalyst surface

- $\quad$ electron location on carbon atom of aromatic ring

A aromatics

b model parameter vector containing the estimated parameter values

$\mathrm{C}_{j} \quad$ surface concentration of component $j\left(\mathrm{~mol} \mathrm{~kg}_{\mathrm{cat}}{ }^{-1}\right)$

$C_{*} \quad$ free site concentration $\left(\mathrm{mol} \mathrm{kg}_{\mathrm{kat}}{ }^{-1}\right)$

CA cycloalkane

$E_{\mathrm{a}} \quad$ activation energy $\left(\mathrm{J} \mathrm{mol}^{-1}\right)$

$\mathrm{F}$ molar flow rate $\left(\mathrm{mol} \mathrm{s}^{-1}\right)$

$F$ value $F$ value for the significance of the regression

g gas

$\mathrm{H} \quad$ enthalpy $\left(\mathrm{J} \mathrm{mol}^{-1}\right)$

$k$ rate coefficient of elementary step $\left(\mathrm{kg}_{\mathrm{kat}} \mathrm{mol}^{-1} \mathrm{~s}^{-1}\right)$

$K \quad$ reaction equilibrium coefficient

$K_{i} \quad$ chemisorption equilibrium coefficient for species $i$ $\left(\mathrm{Pa}^{-1}\right)$

$m$ number of unsaturated carbon atoms adjacent to reacting carbon atom (-)

$n \quad$ degree of branching of reacting carbon atom (-)

$n_{\mathrm{e}} \quad$ number of single-events (-)

nob number of observation

npar number of parameters

nresp number of responses

$p_{\mathrm{t}} \quad$ total pressure $(\mathrm{Pa})$

$p_{i} \quad$ partial pressure of component $i(\mathrm{~Pa})$

$r \quad$ reaction rate $\left(\mathrm{mol} \mathrm{kg}_{\mathrm{cat}}{ }^{-1} \mathrm{~s}^{-1}\right)$

$R_{i} \quad$ net production rate of component $i\left(\mathrm{~mol} \mathrm{~kg}_{\mathrm{cat}}{ }^{-1} \mathrm{~s}^{-1}\right)$

$S \quad$ entropy $\left(\mathrm{J} \mathrm{mol}^{-1} \mathrm{~K}^{-1}\right)$

SEMK Single-Event MicroKinetics

SSQ sum of squared residual between the experimental and model calculated outlet molar flow rates $\left(\mathrm{mol}^{2} \mathrm{~s}^{-2}\right)$

$T \quad$ temperature $(\mathrm{K})$

$\mathrm{t}$ Student $\mathrm{t}$ value for the significance of an individual parameter (-)

$W \quad$ catalyst mass $(\mathrm{kg})$
$X \quad$ conversion $\left(\mathrm{mol} \mathrm{mol}^{-1}\right)$

\section{Greek Symbols}

$\beta \quad$ model parameter vector containing the estimated parameter values

$\Delta \quad$ difference

$\gamma_{\mathrm{H} 2 / \mathrm{A}}$ molar hydrogen to aromatics ratio (-)

$\phi \quad$ contribution factor

$\sigma \quad$ symmetry number

\section{Subscripts}

cat catalyst

d disappearance

deh dehydrogenation

$\mathrm{DMCH}$ dimethyl cyclohexane

glob global

$\mathrm{H}$ hydrogen

hyd hydrogenation

$\mathrm{HC}$ hydrocarbon

$i \rightarrow j \quad$ component/intermediate $i$ to component/intermedi-

ate $j$

j experimental observation index

$\mathrm{MCH}$ methyl cyclohexane

$\mathrm{T}$ toluene

$\mathrm{X} \quad o$-xylene

\section{Superscripts}

$\wedge$ model calculated

$\sim \quad$ intrinsic, single-event

$\neq \quad$ activated complex

hyd/deh via hydrogenation and dehydrogenation

o reactor inlet value

o pre-exponential factor $\left(\mathrm{Pa}^{-1}, \mathrm{~s}^{-1}\right)$

$r$ reactant

sec secondary ring carbon atom

ter tertiary ring carbon atom

\section{REFERENCES}

(1) Cooper, B. H.; Donnis, B. B. L. Appl. Catal., A 1996, 137 (2), 203223.

(2) Nag, N. K. Appl. Catal. 1984, 10 (1), 53-62.

(3) Sapre, A. V.; Gates, B. C. Ind. Eng. Chem. Proc. Des. Dev. 1981, 20

(1), 68-73.

(4) Girgis, M. J.; Gates, B. C. Ind. Eng. Chem. Res. 1991, 30 (9), 20212058.

(5) Aubert, C.; Durand, R.; Geneste, P.; Moreau, C. J. Catal. 1988, 112

(1), $12-20$.

(6) Rautanen, P. A.; Lylykangas, M. S.; Aittamaa, J. R.; Krause, A. O. I. Stud. Surf. Sci. Catal. 2001, 133, 309-316.

(7) Corma, A.; Iglesias, M.; Sanchez, F. Catal. Lett. 1995, 32 (3-4), 313-318.

(8) Keane, M. A.; Patterson, P. M. Ind. Eng. Chem. Res. 1999, 38 (4), 1295-1305.

(9) Rynkowski, J.; Rajski, D.; Szyszka, I.; Grzechowiak, J. R. Catal. Today 2004, 90 (1-2), 159-166.

(10) Smeds, S.; Murzin, D.; Salmi, T. Appl. Catal., A 1997, 150 (1), 115-129.

(11) Mirodatos, C.; Dalmon, J. A.; Martin, G. A. J. Catal. 1987, 105 (2), 405-415.

(12) Rahaman, M. V.; Vannice, M. A. J. Catal. 1991, 127 (1), 267-275.

(13) Lindfors, L. P.; Salmi, T.; Smeds, S. Chem. Eng. Sci. 1993, 48 (22), 3813-3828.

(14) Lin, S. D.; Vannice, M. A. J. Catal. 1993, 143 (2), 563-572.

(15) Vanmeerten, R. Z. C.; Coenen, J. W. E. J. Catal. 1977, 46 (1), 1324.

(16) Thybaut, J. W.; Saeys, M.; Marin, G. B. Chem. Eng. J. 2002, 90 (12), 117-129. 
(17) Saeys, M.; Reyniers, M. F.; Neurock, M.; Marin, G. B. J. Phys. Chem. B 2005, 109 (6), 2064-2073.

(18) Saeys, M.; Reyniers, M. F.; Thybaut, J. W.; Neurock, M.; Marin, G. B. J. Catal. 2005, 236 (1), 129-138.

(19) Froment, G. F. Catal. Rev.- Sci. Eng. 2005, 47 (1), 83-124.

(20) Park, T. Y.; Froment, G. F. Ind. Eng. Chem. Res. 2001, 40 (20), $4172-4186$.

(21) Feng, W.; Vynckier, E.; Froment, G. F. Ind. Eng. Chem. Res. 1993, 32 (12), 2997-3005.

(22) Dewachtere, N. V.; Santaella, F.; Froment, G. F. Chem. Eng. Sci. 1999, 54 (15-16), 3653-3660.

(23) Beirnaert, H. C.; Alleman, J. R.; Marin, G. B. Ind. Eng. Chem. Res. 2001, 40 (5), 1337-1347.

(24) Svoboda, G. D.; Vynckier, E.; Debrabandere, B.; Froment, G. F. Ind. Eng. Chem. Res. 1995, 34 (11), 3793-3800.

(25) Martens, G. G.; Marin, G. B.; Martens, J. A.; Jacobs, P. A.; Baron, G. V. J. Catal. 2000, 195 (2), 253-267.

(26) Martens, G. G.; Thybaut, J. W.; Marin, G. B. Ind. Eng. Chem. Res. 2001, 40 (8), 1832-1844.

(27) Thybaut, J. W.; Marin, G. B. Chem. Eng. Technol. 2003, 26 (4), 509-514.

(28) Thybaut, J. W.; Marin, G. B.; Baron, G. V.; Jacobs, P. A.; Martens,

J. A. J. Catal. 2001, 202 (2), 324-339.

(29) Lozano-Blanco, G.; Thybaut, J. W.; Surla, K.; Galtier, P.; Marin, G. B. Ind. Eng. Chem. Res. 2008, 47 (16), 5879-5891.

(30) Bera, T.; Thybaut, J. W.; Marin, G. B. Ind. Eng. Chem. Res. 2011, 50 (23), 12933-12945.

(31) Martens, J. A.; Parton, R.; Uytterhoeven, L.; Jacobs, P. A.; Froment, G. F. Appl. Catal. 1991, 76 (1), 95-116.

(32) Neurock, M. J. Catal. 2003, 216 (1-2), 73-88.

(33) Somorjai, G. A. Chemistry in two dimensions: surfaces; Cornell University Press: Ithaca, NY, 1981; p 575.

(34) Steijns, M.; Froment, G. F. Ind. Eng. Chem. Prod. Res. Dev. 1981, 20 (4), 660-668.

(35) Bos, A. N. R.; Lefferts, L.; Marin, G. B.; Steijns, M. H. G. M. Appl. Catal., A 1997, 160 (1), 185-190.

(36) Berger, R. J.; Stitt, E. H.; Marin, G. B.; Kapteijn, F.; Moulijn, J. A. Cattech 2001, 5 (1), 30-60.

(37) Marquardt, D. W. J. Soc. Ind. Appl. Math. 1963, 11 (2), 431-441.

(38) NETLIB, http://www.netlib.org.

(39) Powell, M. J. D. A Hybrid Method for Nonlinear Equations. In Numerical Methods for Nonlinear Algebraic Equations; Rabinowitz, P., Ed.; Gordon and Breach Science Publishers: New York, 1988.

(40) Qi, C.; Hoebink, J. H. B. J.; Marin, G. B. Ind. Eng. Chem. Res. 1991, 30 (9), 2088-2097.

(41) Quintana-Solorzano, R.; Thybaut, J. W.; Galtier, P.; Marin, G. B. Catal. Today 2007, 127 (1-4), 17-30.

(42) Vanmeerten, R. Z. C.; Degraaf, T. F. M.; Coenen, J. W. E. J. Catal. 1977, 46 (1), 1-12.

(43) Huang, T. C.; Kang, B. C. Ind. Eng. Chem. Res. 1995, 34 (9), 2955-2963.

(44) Saeys, M.; Reyniers, M. F.; Marin, G. B.; Neurock, M. J. Phys. Chem. B 2002, 106 (30), 7489-7498.

(45) Vynckier, E., Froment, G. F. Modelling of the kinetics of complex processes based upon elementary steps; Elsevier: Amsterdam, The Netherlands, 1991; pp 131-161.

(46) Dumesic, J. A., Rudd, D. F., Aparicio, L. M., Rekoske, J. E., Treviño, A. A. The Microkinetics of Heterogeneous Catalysis; Americal Chemical Society: Washington, DC, 1993.

(47) Campbell, C. T.; Sun, Y. K.; Weinberg, W. H. Chem. Phys. Lett. 1991, 179 (1-2), 53-57.

(48) Toppinen, S.; Rantakyla, T. K.; Salmi, T.; Aittamaa, J. Ind. Eng. Chem. Res. 1996, 35 (6), 1824-1833.

(49) Toppinen, S.; Rantakyla, T. K.; Salmi, T.; Aittamaa, J. Ind. Eng. Chem. Res. 1996, 35 (12), 4424-4433.

(50) Kubicka, D.; Salmi, T.; Murzin, D. Y. Catal. Today 2005, 100 (34), 453-456.

(51) Lin, S. D.; Vannice, M. A. J. Catal. 1993, 143 (2), 539-553.
(52) Backman, H.; Neyestanaki, A. K.; Murzin, D. Y. J. Catal. 2005, 233 (1), 109-118. 